\title{
Anti-Inflammatory Activity of Geldanamycin and Its Derivatives in LPS-Induced RAW 264.7 Cells
}

\section{Thongchai Taechowisan ${ }^{1}$, Winyou Puckdee², Watcharee Waratchareeyakul ${ }^{3}$, Waya S. Phutdhawong ${ }^{4}$}

\author{
${ }^{1}$ Department of Microbiology, Faculty of Science, Silpakorn University, Nakhon Pathom, Thailand \\ ${ }^{2}$ Department of Biology, Faculty of Science and Technology, Rambhai Barni Rajabhat University, Chanthaburi, Thailand \\ ${ }^{3}$ Department of Chemistry, Faculty of Science and Technology, Rambhai Barni Rajabhat University, Chanthaburi, Thailand \\ ${ }^{4}$ Department of Chemistry, Faculty of Science, Silpakorn University, Nakhon Pathom, Thailand \\ Email: *tewson84@hotmail.com
}

How to cite this paper: Taechowisan, T., Puckdee, W., Waratchareeyakul, W. and Phutdhawong, W.S. (2019) Anti-Inflammatory Activity of Geldanamycin and Its Derivatives in LPS-Induced RAW 264.7 Cells. Advances in Microbiology, 9, 398-421. https://doi.org/10.4236/aim.2019.94024

Received: March 28, 2019

Accepted: April 26, 2019

Published: April 29, 2019

Copyright $\odot 2019$ by author(s) and Scientific Research Publishing Inc. This work is licensed under the Creative Commons Attribution International License (CC BY 4.0).

http://creativecommons.org/licenses/by/4.0/

(c) (i) Open Access

\begin{abstract}
Geldanamycin (1) had been isolated as a major compound from Streptomyces zerumbet W14; an endophyte of Zingiber zerumbet (L.) Smith. Two new geldanamycin derivatives; 17-(tryptamine)-17-demethoxygeldanamycin (2) and 17-(5'-methoxytryptamine)-17-demethoxygeldanamycin (3) were synthesized and their anti-inflammatory activity was evaluated in LPS-induced macrophage RAW 264.7 cells by investigating their effects on the inhibition of production of NO, PGE 2 , TNF- $\alpha$, IL- $1 \beta$, IL- 6 and IL-10. The data obtained were consistent with the modulation of TNF- $\alpha$, IL- $1 \beta$, IL- 6 , IL-10 production by these derivatives at concentration of 1 to $5 \mu \mathrm{g} / \mathrm{ml}$. A similar effect was also observed when LPS-induced $\mathrm{NO}$ release and $\mathrm{PGE}_{2}$ production were tested. The inhibitory effects were shown in concentration-dependent manners. From the obtained results, it was concluded that two new geldanamycin derivatives possess anti-inflammatory activity on LPS-induced RAW 264.7 cells. They could be useful for the management of inflammatory diseases.
\end{abstract}

\section{Keywords}

Anti-Inflammatory Activity, Geldanamycin Derivatives, Streptomyces zerumbet, RAW 264.7 Cells

\section{Introduction}

Geldanamycin molecule composes of a benzoquinone structure and a planar 
macrocyclic ansamycin bridge. The target of geldanamycin is heat shock protein 90 (Hsp90), it deactivates Hsp90 specifically to inhibit tumor growth or virus replication and also interfere normal function of Hsp90 in normal cells [1]. The synthesized a series of new 17- and 19-modified derivatives of geldanamycin to obtain new types of Hsp90 inhibitor with weaker toxicities and higher efficiencies have been attempting [2]-[9]. In our previous study, geldanamycin had been isolated as a major compound from Streptomyces zerumbet W14; an endophyte of Zingiber zerumbet (L.) Smith. It had in vitro anti-inflammatory activity on LPS-induced RAW 264.7 cells by inhibition of mRNA expression and production of inducible NO synthase (iNOS), tumor necrosis factor-alpha (TNF- $\alpha$ ), interleukin-1 $\beta$ (IL-1 $\beta$ ), and interleukin-6 (IL-6) [10].

Tryptamine, a monoamine alkaloid containing an indole ring structure was derived by the decarboxylation of amino acid tryptophan. Tryptamine played important biomedical role as neurotransmitter and neuromodulator, vasoconstrictor and vasodilator, antibacterial, antifungal and antioxidant agents [11]. Its modification at different position led to many compounds of pharmacological importance. Recently, tryptamine-gallic acid hybrid molecule have been synthesized as SEGA (3a), which prevented non-steroidal anti-inflammatory druginduced mitochondrial pathology, apoptosis, and gastropathy by blocking mitochondrial oxidative stress, chelating intramitochondrial free iron, and correcting mitochondrial pathology entering into mitochondria [12]. According to this effect, the invention of tryptamine-geldanamycin hybrids has been designed and evaluated the in vitro anti-inflammatory activity. The C17 methoxyl of geldanamycin molecule could allow for the introduction of various nucleophiles, hence geldanamycin from the beginning had been apopular template for semisynthetic analogs [2]-[9].

In this study, a novel 17-substituted geldanamycin derivatives with tryptamine and 5-methoxytryptamine were synthesized and their anti-inflammatory activity was evaluated on LPS-activated macrophage RAW 264.7 cells by investigating their effects on the inhibition of production of NO, PGE 2 , TNF- $\alpha$, IL-1 $\beta$, IL-6 and IL-10.

\section{Materials and Methods}

\subsection{Extraction and Isolation}

Streptomyces zerumbet W14 was isolated from the rhizome of Zingiber zerumbet (L.) Smith by surface-sterilization technique and identified by morphological, cultural, physiological and biochemical characteristics and also 16S rDNA gene sequencing as described by Taechowisan et al. [10]. This strain was grown on ISP-2 agar at $30^{\circ} \mathrm{C}$ for 14 days and then the culture medium was cut into small pieces that were extracted with ethyl acetate $(3 \times 500 \mathrm{ml})$. This organic solvent was pooled and then taken to dryness under rotary evaporation to give a dark brown solid. The solid was separated by column chromatography using silica gel 
60 (Merck, $0.040-0.063 \mathrm{~mm}$ ) and 30\%, 50\%, 75\% and 100\% of ethyl acetate in hexane as the eluent to give 17 main fractions (F1-F17). Fraction F13 (30.3 mg) gave a very prominent single spot of pure compound on TLC and was undertaken to investigate on NMR spectroscopy. The spectral data revealed this compound to be geldanamycin (1).

\subsection{Synthesis of Geldanamycin Derivatives}

The following experimental information was representative and describes the complete details of geldanamycin derivative synthesis.

Geldanamycin derivatives; 17-(tryptamine)-17-demethoxygeldanamycin (2) and 17-(5'-methoxytryptamine)-17-demethoxygeldanamycin (3) were synthesized from geldanamycin (Figure 1$)$; To a solution of geldanamycin $(0.84 \mathrm{~g}, 100$ $\mathrm{mmol})$ in dichloromethane $(15 \mathrm{ml})$ at $25^{\circ} \mathrm{C}$ was added tryptamine $(0.29 \mathrm{~g}, 150$ mmol) (Sigma-Aldrich) or 5'-methoxytryptamine (0.36 g, $150 \mathrm{mmol}$ ) (SigmaAldrich). The reaction mixture was stirred at $25^{\circ} \mathrm{C}$ for 30 minutes before addition of saturated aqueous $\mathrm{CaCl}_{2}(5 \mathrm{ml})$. The organic layer was removed and washed with saturated $\mathrm{CaCl}_{2}$ solution $(3 \times 5 \mathrm{ml})$ and dried $\left(\mathrm{Na}_{2} \mathrm{SO}_{4}\right)$. The mixture was filtered over Celite, rinsed with ethyl acetate, and concentrated under reduced pressure to give a dark purple solid. Purification by flash chromatography (silica, 60\% ethyl acetate/hexanes) affords 17-(tryptamine)-17-demetho-xygeldanamycin (1.01 g, $97 \mathrm{mmol}, 96.8 \%)$ or 17-(5'-methoxytryptamine)-17-demethoxygeldanamycin (1.03 g, $95 \mathrm{mmol}, 94.7 \%)$ (Figure 2).

\subsection{Cell Culture and Sample Treatment}

RAW 264.7 murine macrophage cell line was obtained from the Korean Cell Line Bank (Seoul, Korea). These cells were grown at $37^{\circ} \mathrm{C}$ in DMEM medium supplement with $10 \%$ FBS, penicillin (100 units/ml), and streptomycin sulfate $(100 \mu \mathrm{g} / \mathrm{ml})$ in a humidified atmosphere of $5 \% \mathrm{CO}_{2}$. Cells were incubated with the compound at increasing concentrations and stimulated with LPS $1 \mu \mathrm{g} / \mathrm{ml}$ for $24 \mathrm{~h}$.

\subsection{MTT Assay for Cell Viability}

Cytotoxicity studies were performed on a 96-well plate. RAW 264.7 cells were mechanically scraped and plated $2 \times 10^{5}$ per well on 96-well plate containing 100 $\mu \mathrm{l}$ of DMEM medium with $10 \%$ FBS and incubated overnight. The compounds were dissolved in dimethylsulfoxide (DMSO) for stock solution. The DMSO concentrations in all assays did not exceed $0.1 \%$. Twenty-four $\mathrm{h}$ after seeding, $100 \mu \mathrm{l}$ new media or test compound was added, and the plates were incubated for $24 \mathrm{~h}$. Cells were washed once before adding $50 \mu \mathrm{l} \mathrm{FBS-free} \mathrm{medium} \mathrm{contain-}$ ing $5 \mathrm{mg} / \mathrm{ml} \mathrm{MTT}$. After $4 \mathrm{~h}$ of inoculation at $37^{\circ} \mathrm{C}$, the medium was discarded and the formazan blue, which formed in the cells, was dissolved in $50 \mu$ DMSO. The optical density was measured at $450 \mathrm{~nm}$. The concentration required for reducing the absorbance by $50 \%\left(\mathrm{IC}_{50}\right)$ compared to the control cells was determined. 


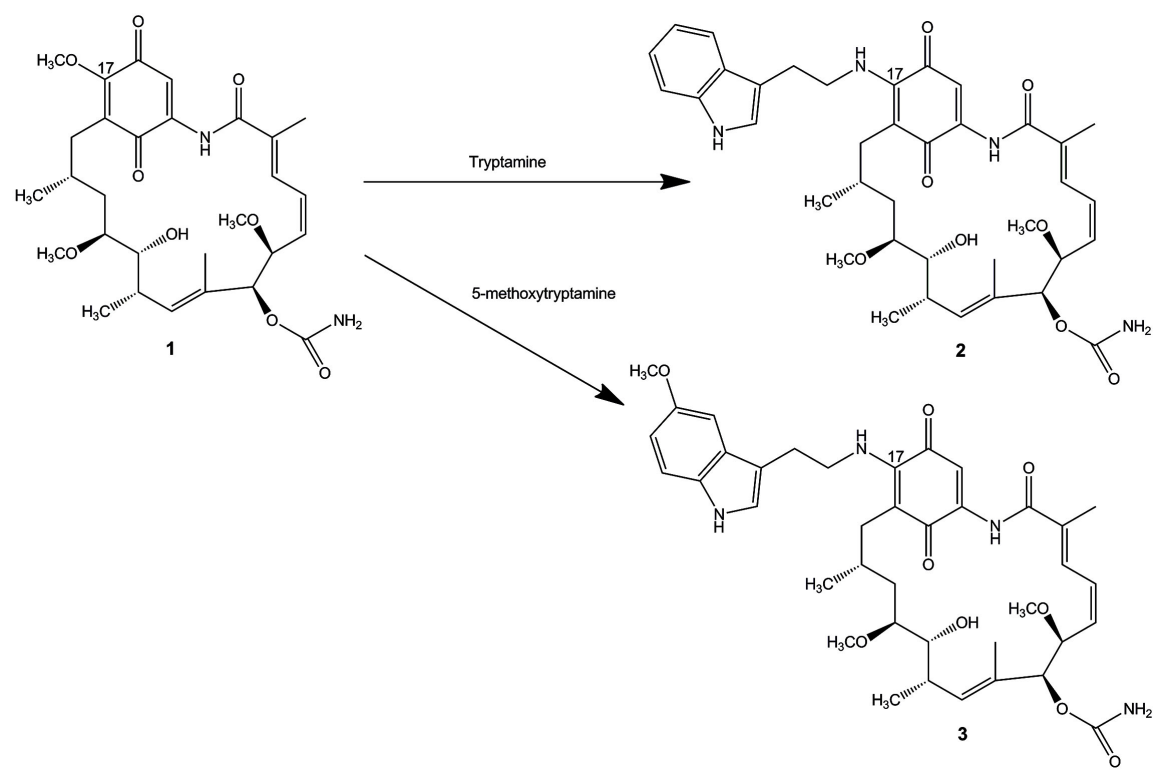

Figure 1. Geldanamycin chemical structure (1) and structures and synthesis of two derivatives; 17-(tryptamine)-17-demethoxygeldanamycin (2) and 17-(5'methoxytryptamine)-17-demethoxygeldanamycin (3).

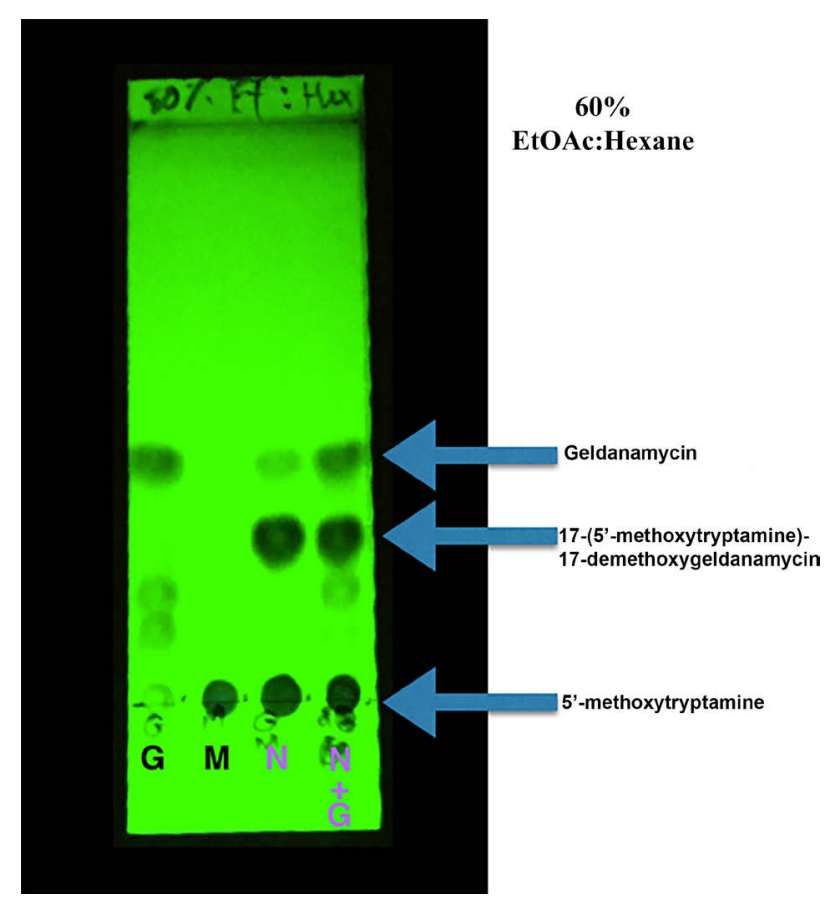

Figure 2. Silica gel TLC $\left(\mathrm{GF}_{254}\right)$ of geldanamycin derivative synthesis; 17-(5'-methoxytryptamine)-17-demethoxygeldanamycin on $60 \%$ of ethyl acetate in hexane after color reaction with vanillin-sulfuric acid. (G: Geldanamycin, M: 5'-methoxytryptamine, N: New compound synthesis, N + G: New compound synthesis plus geldanamycin.

\subsection{Nitrite Assay}

Nitrite accumulation, an indicator of NO synthesis, was measured in the culture medium by Griess reaction [13]. Briefly, $100 \mu \mathrm{l}$ of cell culture medium was 
mixed with $100 \mu \mathrm{l}$ of Griess reagent [equal volumes of $1 \%(\mathrm{w} / \mathrm{v})$ sulfanilamide in $5 \%(\mathrm{v} / \mathrm{v})$ phosphoric acid and $0.1 \%(\mathrm{w} / \mathrm{v})$ naphthylethylenediamine- $\mathrm{HCl}\}$ and incubated at room temperature for $100 \mathrm{~min}$, and then the absorbance at $550 \mathrm{~nm}$ was measured in a microplate reader. Fresh culture medium was used as the blank in all experiments. The amount of nitrite in the samples was calculated from a sodium nitrite standard curve freshly prepared in culture medium.

\section{6. $\mathrm{PGE}_{2}$, TNF- $\alpha$, IL-1 $\beta$, IL-6 and IL-10 Assay}

PGE $_{2}$, TNF- $\alpha$, IL- $1 \beta$, IL-6 and IL-10 level in macrophage culture medium were quantified by ELISA kits (PeproTech, NJ, USA) according to the manufacturer's instructions.

\subsection{Data Analysis}

All calculations were done using the SPSS version 15 statistical software package for analysis of the data. The data were presented as means \pm SEM values of three independent determinations and statical analysis carried out using one-way ANOVA. Differences were considered to be of statistical significance at an error probability of less than $0.05(p<0.05)$.

\section{Results}

\subsection{Synthesis of Geldanamycin Derivatives}

The mass spectral data of geldanamycin and geldanamycin derivatives were carried out by ${ }^{1} \mathrm{H}-\mathrm{NMR},{ }^{13} \mathrm{C}-\mathrm{NMR}$ as following.

Compound (1): The IR spectrum displayed characteristic absorption bands of $\mathrm{NH}$ and $\mathrm{OH}$ stretches at $\mathrm{n} 3478,3440,3336$ and $3297 \mathrm{~cm}^{-1}$, $\mathrm{CH}$ stretch in $\mathrm{CH}_{3}$ and $\mathrm{CH}_{2}$ at $\mathrm{n} 2927 \mathrm{~cm}^{-1}, \mathrm{CH}$ stretch in methyl ether at $\mathrm{n} 2853 \mathrm{~cm}^{-1}, \mathrm{C}=\mathrm{O}$ stretch in $\mathrm{OCONH}_{2}$ at $\mathrm{n} 1729 \mathrm{~cm}^{-1}, \mathrm{C}=\mathrm{O}$ stretch in a,b-unsaturated amide at $\mathrm{n} 1701$ $\mathrm{cm}^{-1}$ and $\mathrm{C}=\mathrm{O}$ stretches in quinone at $\mathrm{n} 1675$ and $1652 \mathrm{~cm}^{-1}$. The MS gave a $[\mathrm{M}+\mathrm{Na}]^{+}$ion at $\mathrm{m} / z 583.2571$ which corresponded to the molecular formula $\mathrm{C}_{29} \mathrm{H}_{40} \mathrm{~N}_{2} \mathrm{O}_{9}$ for the compound indicating eleven double bond equivalents in the molecule. The structure was fully elucidated by ${ }^{1} \mathrm{H}$ NMR, ${ }^{13} \mathrm{C}$ NMR spectrosopy, DEPT-135, and 2D NMR spectral studies. The ${ }^{1} \mathrm{H}-\mathrm{NMR}$ spectral data (DMSOd6) of compound 1 showed four methyl groups at $\delta_{\mathrm{H}} 0.75(3 \mathrm{HJ}=6.8 \mathrm{~Hz}), 0.97$ $(3 \mathrm{H}, \mathrm{brs}), 1.62(3 \mathrm{H}, \mathrm{s})$ and $1.93(3 \mathrm{H}, \mathrm{s})$ three methoxy protons at $\delta_{\mathrm{H}} 3.23(3 \mathrm{H}, \mathrm{s})$, $3.24(3 \mathrm{H}, \mathrm{s})$ and $3.96(3 \mathrm{H}, \mathrm{s})$, five olefin protons at $\delta_{\mathrm{H}} 5.50(1 \mathrm{H}, \mathrm{d}, J=8.5 \mathrm{~Hz})$, $5.81(1 \mathrm{H}, \mathrm{br}), 6.58(1 \mathrm{H}, \mathrm{t}), 6.95(1 \mathrm{H}, \mathrm{d})$ and $7.04(1 \mathrm{H}, \mathrm{s})$, four oxygenated methines at $\delta_{\mathrm{H}} 3.09(2 \mathrm{H}, \mathrm{br}), 4.36(1 \mathrm{H}, \mathrm{d}, J=7.6 \mathrm{~Hz})$ and $4.88(1 \mathrm{H}, \mathrm{br})$, amine hydrogen at dH $9.18(1 \mathrm{H}, \mathrm{br})$, two methanefriyl group at $\delta_{\mathrm{H}} 1.93(1 \mathrm{H}, \mathrm{s})$ and 2.56 $(1 \mathrm{H})$ and methanediyl groups at $\delta_{\mathrm{H}} 1.45(2 \mathrm{H}, \mathrm{br}), 2.18(1 \mathrm{H}, \mathrm{dd}, J=4.8$ and 12.5 $\mathrm{Hz})$ and $2.43(1 \mathrm{H}, \mathrm{dd}, J=9.9$ and $12.5 \mathrm{~Hz}) \mathrm{ppm}$. The ${ }^{13} \mathrm{C}-\mathrm{NMR}$ spectrum exhibited 39 signals which were classified by the DEPT-135 and HMQC spectra as four methyl carbons at $\delta_{\mathrm{C}} 12.8(2-\mathrm{Me}), 13.0(8-\mathrm{Me}), 13.4(8-\mathrm{Me})$ and 23.9 (14-Me), three methoxy carbons at $\delta_{\mathrm{C}} 56.5$ (12-OMe), $57.1(6-\mathrm{OMe})$, and 61.6 
(17-OMe), five olefin carbons at $\delta_{\mathrm{C}} 111.3$ (C-19), 126.3 (C-4), 128.7 (C-3), 132.4 $(\mathrm{C}-9)$ and 138.7 (C-5), five quarternary olefin carbons at $\delta_{\mathrm{C}} 128.7$ (C-16), 129.1 (C-8), 133.2 (C-2), 140.1 (C-20) and 156.9 (C-17), two methanetriyl carbons at $\delta_{\mathrm{C}} 27.1(\mathrm{C}-14)$ and $32.6(\mathrm{C}-10)$, two methanediyl carbons at $\delta_{\mathrm{C}} 31.3(\mathrm{C}-13)$ and 32.2 (C-15), four oxygenated methines at $\delta_{\mathrm{C}} 72.4(\mathrm{C}-11), 80.7$ (C-12), 81.1 (C-7) and $82.3(\mathrm{C}-6)$, four carbonyl carbons at $\delta_{\mathrm{C}} 156.6\left(7-\mathrm{OCONH}_{2}\right), 169.7(\mathrm{C}-1)$, $183.6(\mathrm{C}-21)$ and $184.3(\mathrm{C}-18)$. The ${ }^{1} \mathrm{H}-{ }^{1} \mathrm{H}$ COSY spectrum revealed the connectivity, in DMSO-d6 from H-3 through $\mathrm{H}-4$; H-4 through $\mathrm{H}-3$ and $\mathrm{H}-5 ; \mathrm{H}-5$ through $\mathrm{H}-4$ and $\mathrm{H}-6$; $\mathrm{H}-6$ through $\mathrm{H}-5$ and $\mathrm{H}-7$; $\mathrm{H}-7$ through $\mathrm{H}-6 ; \mathrm{H}-9$ through $\mathrm{H}-10 ; \mathrm{H}-12$ through $\mathrm{H}-9$ and $10-\mathrm{Me} ; 10-\mathrm{Me}$ through $\mathrm{H}-10 ; \mathrm{H}-12$ through $\mathrm{H}-13$; H-13 through $\mathrm{H}-12$ and $\mathrm{H}-14 ; \mathrm{H}-14$ through $\mathrm{H}-13,14-\mathrm{Me}$ and $\mathrm{H}-15$; 14-Me through $\mathrm{H}-14$ and $\mathrm{H}-15$ through $\mathrm{H}-14$. The HMBC spectrum showed the following long-range correlations; 2-Me $\left(\delta_{\mathrm{H}} 1.93\right)$ to $\mathrm{C}-1\left(\delta_{\mathrm{C}} 169.7\right)$, C-2 $\left(\delta_{\mathrm{H}} 133.2\right)$ to $\mathrm{C}-3\left(\delta_{\mathrm{C}} 128.7\right)$ and C-4 $\left(\delta_{\mathrm{C}} 126.3\right) ; \mathrm{H}-4\left(\delta_{\mathrm{H}} 6.58\right)$ to C-2 $\left(\delta_{\mathrm{C}}\right.$ $133.2)$ and $\mathrm{C}-6\left(\delta_{\mathrm{C}} 82.3\right)$; H-6 $\left(\delta_{\mathrm{H}} 4.36\right)$ to $\mathrm{C}-4\left(\delta_{\mathrm{C}} 126.3\right), 6-\mathrm{OMe}\left(\delta_{\mathrm{C}} 57.1\right)$; 6-OMe $\left(\delta_{\mathrm{H}} 3.24\right)$ to C-6 $\left(\delta_{\mathrm{C}} 82.3\right)$; H-7 $\left(\delta_{\mathrm{H}} 4.88\right)$ to C-5 $\left(\delta_{\mathrm{C}} 138.7\right), 7-\mathrm{OCONH}_{2}$ $\left(\delta_{\mathrm{C}} 156.6\right), \mathrm{C}-9\left(\delta_{\mathrm{C}} 132.4\right)$ and $8-\mathrm{Me}\left(\delta_{\mathrm{C}} 13.0\right) ; 8-\mathrm{Me}\left(\delta_{\mathrm{H}} 1.62\right)$ to C-7 $\left(\delta_{\mathrm{C}} 81.1\right)$ and C-9 $\left(\delta_{\mathrm{C}} 132.4\right)$; H-9 $\left(\delta_{\mathrm{H}} 5.50\right)$ to C-7 $\left(\delta_{\mathrm{C}} 81.1\right)$, and 8-Me $\left(\delta_{\mathrm{C}} 13.0\right) ; 10-\mathrm{Me}$ $\left(\delta_{\mathrm{H}} 0.75\right)$ to $\mathrm{C}-9\left(\delta_{\mathrm{C}} 132.4\right), \mathrm{C}-10\left(\delta_{\mathrm{C}} 32.6\right)$, and C-11 $\left(\delta_{\mathrm{C}} 72.4\right) ; \mathrm{H}-11\left(\delta_{\mathrm{H}} 3.09\right)$ to $10-\mathrm{Me}\left(\delta_{\mathrm{C}} 13.4\right) ; \mathrm{H}-12\left(\delta_{\mathrm{H}} 3.09\right)$ to $12-\mathrm{OMe}\left(\delta_{\mathrm{C}} 56.5\right) ; 12-\mathrm{OMe}\left(\delta_{\mathrm{H}} 3.23\right)$ to $\mathrm{C}-12$ $\left(\delta_{\mathrm{C}} 80.7\right) ; \mathrm{H}-13\left(\delta_{\mathrm{H}} 1.45\right)$ to $14-\mathrm{Me}\left(\delta_{\mathrm{C}} 23.9\right) ; \mathrm{H}-14\left(\delta_{\mathrm{H}} 1.93\right)$ to $\mathrm{C}-12\left(\delta_{\mathrm{C}} 80.7\right)$ and C-16 $\left(\delta_{\mathrm{C}} 128.7\right) ; 14-\mathrm{Me}\left(\delta_{\mathrm{H}} 0.97\right)$ to C-14 $\left(\delta_{\mathrm{C}} 27.1\right)$ and $\mathrm{C}-15\left(\delta_{\mathrm{C}} 32.2\right) ; \mathrm{H}-15$ $\left(\delta_{\mathrm{H}} 2.18,2,43\right)$ to $\mathrm{C}-13\left(\delta_{\mathrm{C}} 31.3\right), \mathrm{C}-14\left(\delta_{\mathrm{C}} 27.1\right), \mathrm{C}-16\left(\delta_{\mathrm{C}} 128.7\right), \mathrm{C}-17\left(\delta_{\mathrm{C}} 156.9\right)$ and $\mathrm{C}-21\left(\delta_{\mathrm{C}} 183.6\right) ; 17-\mathrm{OMe}\left(\delta_{\mathrm{H}} 3.96\right)$ to $\mathrm{C}-17\left(\delta_{\mathrm{C}} 156.9\right)$ and $\mathrm{NH}\left(\delta_{\mathrm{H}} 9.18\right)$ to C-1 $\left(\delta_{\mathrm{C}} 169.7\right), \mathrm{C}-19\left(\delta_{\mathrm{C}} 111.3\right)$ and C-21 $\left(\delta_{\mathrm{C}} 183.6\right)$. The spectral data revealed the compound 1 to be geldanamycin. Its ${ }^{1} \mathrm{H}$ - and ${ }^{13} \mathrm{C}-\mathrm{NMR}$ spectral data of which were in good agreement with those of geldanamycin (Table 1) previously reported by Ōmura et al. [14] and Qin and Panek [15].

Compound (2): The MS gave a $[\mathrm{M}+\mathrm{Na}]^{+}$ion at $\mathrm{m} / z 711.3384$ which corresponded to the molecular formula $\mathrm{C}_{38} \mathrm{H}_{48} \mathrm{~N}_{4} \mathrm{O}_{8}$. The structure was fully elucidated by ${ }^{1} \mathrm{H}$ NMR, ${ }^{13} \mathrm{C}$ NMR spectrosopy, DEPT-135, and 2D NMR spectral studies. The ${ }^{1} \mathrm{H}-\mathrm{NMR}$ spectral data $\left(\mathrm{CDCl}_{3}\right)$ of compound 2 showed four methyl groups at $\delta_{\mathrm{H}} 0.93(3 \mathrm{H}, \mathrm{d}, J=6.3 \mathrm{~Hz}), 0.99(3 \mathrm{H}, \mathrm{d}, J=6.9 \mathrm{~Hz}), 1.80(3 \mathrm{H}, \mathrm{s})$ and $2.02(3 \mathrm{H}$, $\mathrm{s})$, two methoxy proton at $\delta_{\mathrm{H}} 3.26(3 \mathrm{H}, \mathrm{s})$ and $3.36(3 \mathrm{H}, \mathrm{s})$, five olifin protons at $\delta_{\mathrm{H}} 5.86(1 \mathrm{H}, \mathrm{m}), 5.89(1 \mathrm{H}, \mathrm{m}), 6.58(1 \mathrm{H}, \mathrm{t}, J=12 \mathrm{~Hz}), 6.95(1 \mathrm{H}, \mathrm{d}, J=12 \mathrm{~Hz})$ and $7.24(1 \mathrm{H}, \mathrm{s})$, four oxygenated methines at $\delta_{\mathrm{H}} 3.45(1 \mathrm{H}, \mathrm{m}), 3.57(1 \mathrm{H}, \mathrm{d}, J=9.0$ $\mathrm{Hz}), 4.30(1 \mathrm{H}, \mathrm{d}, J=9.9 \mathrm{~Hz})$ and $5.18(1 \mathrm{H}, \mathrm{s})$, nitrogenated methines at at $\delta_{\mathrm{H}}$ $3.77(1 \mathrm{H}, \mathrm{m})$ and $3.91(1 \mathrm{H}, \mathrm{m})$, five aromatic protons at $\delta_{\mathrm{H}} 7.13(1 \mathrm{H}, \mathrm{d}, \mathrm{m}), 7.14$ $(1 \mathrm{H}, \mathrm{m}), 7.15(1 \mathrm{H}, \mathrm{m}), 7.40(1 \mathrm{H}, \mathrm{d}, J=7.8 \mathrm{~Hz})$ and $7.60(1 \mathrm{H}, \mathrm{d}, J=7.8 \mathrm{~Hz})$, amine hydrogen at $\delta_{\mathrm{H}} 8.25(1 \mathrm{H}, \mathrm{s})$, two methanetriyl groups at $\delta_{\mathrm{H}} 1.77(1 \mathrm{H}, \mathrm{m})$ and $2.74(1 \mathrm{H}, \mathrm{m})$ and three methanediyl groups at $\delta_{\mathrm{H}} 1.77(2 \mathrm{H}, \mathrm{m}), 2.40(1 \mathrm{H}$, $\mathrm{m}), 2.70(1 \mathrm{H}, \mathrm{m})$ and $3.15(1 \mathrm{H}, \mathrm{t}, J=6.6 \mathrm{~Hz}) \mathrm{ppm}$. The ${ }^{13} \mathrm{C}-\mathrm{NMR}$ spectrum exhibited 38 signals which were classified by the DEPT-135 and HMQC spectra as 
Table 1. Comparison of the spectral data of the compound 1 and GDA ${ }^{\mathrm{a}}$.

\begin{tabular}{|c|c|c|c|c|c|c|c|}
\hline No. & $\boldsymbol{\delta}_{\mathrm{C}}$ compound $\mathbf{1}$ & $\delta_{\mathrm{C}} \mathrm{GDA}$ & $\delta_{\mathrm{H}}$ compound 1 & $\delta_{\mathrm{H}} \mathrm{GDA}$ & $\mathrm{HMBC}(\mathrm{H} \rightarrow \mathrm{C})$ & $\operatorname{cosy}$ & NOESY \\
\hline 1 & $169.7 \mathrm{C}$ & 169.1 & - & - & - & - & - \\
\hline 2 & $133.2 \mathrm{C}$ & 133.2 & - & - & - & - & - \\
\hline $2-\mathrm{Me}$ & $12.8 \mathrm{CH}_{3}$ & 12.2 & $1.93 \mathrm{~s}$ & $1.91, \mathrm{~s}$ & $1,2,3,4$ & - & - \\
\hline 3 & $128.7 \mathrm{CH}$ & 128.4 & $6.95 \mathrm{~d}$ & $6.95, \mathrm{~d}$ & - & 4 & $\mathrm{NH}, 4,6,7$ \\
\hline 4 & $126.3 \mathrm{CH}$ & 125.7 & $6.58 \mathrm{t}$ & $6.56, \mathrm{t}$ & 2,6 & 3,5 & 3,5 \\
\hline 5 & $138.7 \mathrm{CH}$ & 137.8 & $5.81 \mathrm{br}$ & $5.80, \mathrm{t}$ & - & 4,6 & 4,6 \\
\hline 6 & $82.3 \mathrm{CH}$ & 81.6 & $4.36 \mathrm{~d}(7.6)$ & $4.34, \mathrm{~d}$ & $4,6-\mathrm{OMe}$ & 5,7 & $3,5,7$ \\
\hline 6-OMe & $57.1 \mathrm{CH}_{3}$ & 56.0 & $3.24 \mathrm{~s}$ & $3.22, \mathrm{~s}$ & 6 & - & - \\
\hline 7 & $81.1 \mathrm{CH}$ & 80.6 & $4.88 \mathrm{br}$ & $4.86, \mathrm{br}$ & $\begin{array}{c}5,7-\mathrm{OCONH}_{2} \\
9,8-\mathrm{Me}\end{array}$ & 6 & $3,6,9$ \\
\hline 7-OCONH & $156.6 \mathrm{C}$ & 156.0 & - & $6.45, \mathrm{br}$ & - & - & - \\
\hline 8 & $129.1 \mathrm{C}$ & 132.6 & - & - & - & - & - \\
\hline 8-Me & $13.0 \mathrm{CH}_{3}$ & 12.5 & $1.62 \mathrm{~s}$ & $1.61, \mathrm{~s}$ & 7,9 & - & 10 \\
\hline 9 & $132.4 \mathrm{CH}$ & 131.9 & $5.50 \mathrm{~d}(8.5)$ & $5.51, \mathrm{~d}$ & 7, 8-Me & 10 & 7 \\
\hline 10 & $32.6 \mathrm{CH}$ & 32.1 & 2.56 & $3.61, \mathrm{~m}$ & - & $9,10-\mathrm{Me}$ & $8-\mathrm{Me}, 10-\mathrm{Me}, 11,12$ \\
\hline $10-\mathrm{Me}$ & $23.4 \mathrm{CH}_{3}$ & 23.3 & $0.75 \mathrm{~d}(6.8)$ & $0.97, \mathrm{~d}$ & $9,10,11$ & 10 & $10,11,12$ \\
\hline 11 & $72.4 \mathrm{CH}$ & 71.9 & $3.09 \mathrm{br}$ & $3.29, \mathrm{~s}$ & $10-\mathrm{Me}$ & - & $10,10-\mathrm{Me}, 13,14$ \\
\hline $11-\mathrm{OH}$ & - & - & - & - & - & - & - \\
\hline 12 & $80.7 \mathrm{CH}$ & 80.2 & $3.09 \mathrm{br}$ & $3.07, \mathrm{~m}$ & $12-\mathrm{OMe}$ & 13 & $10,10-\mathrm{Me}, 13,14$ \\
\hline $12-\mathrm{OMe}$ & $56.5 \mathrm{CH}_{3}$ & 56.6 & $3.23 \mathrm{~s}$ & $3.23, \mathrm{~s}$ & 12 & - & - \\
\hline 13 & $31.3 \mathrm{CH}_{2}$ & 31.0 & $1.45 \mathrm{br}$ & $1.45, \mathrm{~m}$ & $14-\mathrm{Me}$ & 12,14 & $11,12,14$ \\
\hline 14 & $27.1 \mathrm{CH}$ & 26.6 & $1.93 \mathrm{~s}$ & $1.91, \mathrm{br}$ & 12,16 & $13,14-\mathrm{Me}, 15 \mathrm{a}, 15 \mathrm{~b}$ & 13 \\
\hline $14-\mathrm{Me}$ & $23.9 \mathrm{CH}_{3}$ & 23.0 & $0.97 \mathrm{br}$ & $0.76, \mathrm{~d}$ & 14,15 & 14 & - \\
\hline $15 \mathrm{a}$ & & 31.7 & $2.43 \mathrm{dd}(12.5,9.9)$ & $2.42, \mathrm{~m}$ & $13,14,16,17,21$ & $14,15 b$ & - \\
\hline $15 b$ & $32.2 \mathrm{CH}_{2}$ & 31.7 & $2.18 \mathrm{dd}(12.5,4.8)$ & & $13,14,16,17,21$ & $14,15 \mathrm{a}$ & - \\
\hline 16 & $128.7 \mathrm{C}$ & 128.1 & - & - & - & - & - \\
\hline 17 & $156.9 \mathrm{C}$ & 156.4 & - & - & - & - & - \\
\hline 17-OMe & $61.6 \mathrm{CH}_{3}$ & 61.0 & $3.96 \mathrm{~s}$ & $3.93, \mathrm{~s}$ & 17 & - & - \\
\hline 18 & $184.3 \mathrm{C}$ & 183.6 & - & - & - & - & - \\
\hline 19 & $111.3 \mathrm{CH}$ & 110.9 & $7.04 \mathrm{~s}$ & $7.02, \mathrm{~s}$ & - & - & - \\
\hline 20 & $140.1 \mathrm{C}$ & 139.6 & - & - & - & - & - \\
\hline 21 & $183.6 \mathrm{C}$ & 183.1 & - & - & - & - & - \\
\hline $\mathrm{NH}$ & - & - & $9.18, \mathrm{NH}, \mathrm{br}$ & 9.14, NH, br & $1,19,21$ & - & 3 \\
\hline
\end{tabular}

${ }^{\mathrm{a}} \mathrm{GDA}$, geldanamycin (data from Ōmura et al. [14]). ${ }^{1} \mathrm{H}$ and ${ }^{13} \mathrm{C}-\mathrm{NMR}$ assignments for compound $1\left[{ }^{1} \mathrm{H}(400 \mathrm{MHz}),{ }^{13} \mathrm{C}-\mathrm{NMR}(100 \mathrm{MHz}), \mathrm{DMSO}-d 6, J=\right.$ $\mathrm{Hz}]$; Geldanamycin $\left[{ }^{1} \mathrm{H}(400 \mathrm{MHz}),{ }^{13} \mathrm{C}-\mathrm{NMR}(100 \mathrm{MHz})\right.$, DMSO- $\left.d 6, J=\mathrm{Hz}\right]$. 
four methyl carbons at $\delta_{\mathrm{C}} 12.3(10-\mathrm{Me}), 12.5(2-\mathrm{Me}), 12.7(8-\mathrm{Me})$ and 22.8 (14-Me), two methyoxy carbons at $\delta_{\mathrm{C}} 56.7$ (12-OMe) and 57.1 (6-OMe), five olefin carbons at $\delta_{\mathrm{C}} 108.0(\mathrm{C}-19), \delta_{\mathrm{C}} 126.5(\mathrm{C}-4), \delta_{\mathrm{C}} 126.9(\mathrm{C}-3), \delta_{\mathrm{C}} 133.8(\mathrm{C}-9)$ and $\delta_{\mathrm{C}} 135.8(\mathrm{C}-5)$, five quaternary olefin carbons at $\delta_{\mathrm{C}} 108.6(\mathrm{C}-16), 132.7(\mathrm{C}-8)$, $135.0(\mathrm{C}-2), \delta_{\mathrm{C}} 141.4(\mathrm{C}-20)$ and $144.9(\mathrm{C}-17)$, four oxygenated methines at $\delta_{\mathrm{C}}$ 72.6 (C-11), $81.2(\mathrm{C}-6), 81.5(\mathrm{C}-12)$ and 81.7 (C-7), nitrogenated methines at 45.7 (C-22), five aromatic carbons at $\delta_{\mathrm{C}} 111.5$ (C-28), 118.5 (C-31), 119.8 (C-29), $122.5(\mathrm{C}-25)$ and $125.6(\mathrm{C}-30)$, three quaternary aromatic carbons at $\delta_{\mathrm{C}} 111.3$ (C-24), 126.8 (C-27) and 136.6 (C-26), two methanetriyl carbons at $\delta_{\mathrm{C}} 28.5$ $(\mathrm{C}-14)$ and $32.3(\mathrm{C}-10)$, three methanediyl carbons at $\delta_{\mathrm{C}} 25.75(\mathrm{C}-23), 34.4$ $(\mathrm{C}-15)$ and $35.0(\mathrm{C}-13)$ and four carbonyl quaternary carbons at $\delta_{\mathrm{C}} 156.1$ (7-OCONH$\left.{ }_{2}\right), 168.4$ (C-1), 180.5 (C-21) and 183.8 (C-18) ppm.

Compound (3): The MS gave a $[\mathrm{M}+\mathrm{Na}]^{+}$ion at $\mathrm{m} / z 741.3482$ which corresponded to the molecular formula $\mathrm{C}_{39} \mathrm{H}_{50} \mathrm{~N}_{4} \mathrm{O}_{9}$. The structure was fully elucidated by ${ }^{1} \mathrm{H}-\mathrm{NMR},{ }^{13} \mathrm{C}-\mathrm{NMR}$ spectrosopy, DEPT-135, and $2 \mathrm{D}$ NMR spectral studies Table 2. The ${ }^{1} \mathrm{H}-\mathrm{NMR}$ spectral data $\left(\mathrm{CDCl}_{3}\right)$ of compound 3 showed four methyl groups at $\delta_{\mathrm{H}} 0.94(3 \mathrm{H}, \mathrm{d}, J=6.3 \mathrm{~Hz}), 1.00(3 \mathrm{H}, \mathrm{d}, J=6.9 \mathrm{~Hz}), 1.80(3 \mathrm{H}, \mathrm{s})$ and $2.02(3 \mathrm{H}, \mathrm{s})$, three methoxy proton at $\delta_{\mathrm{H}} 3.27(3 \mathrm{H}, \mathrm{s}), 3.36(3 \mathrm{H}, \mathrm{s})$ and 3.87 $(3 \mathrm{H}, \mathrm{s})$, five olifine protons at $\delta_{\mathrm{H}} 5.86(1 \mathrm{H}, \mathrm{m}), 5.89(1 \mathrm{H}, \mathrm{m}), 6.57(1 \mathrm{H}, \mathrm{t}, J=11.4$ $\mathrm{Hz}), 6.95(1 \mathrm{H}, \mathrm{d}, J=11.4 \mathrm{~Hz})$ and $7.24(1 \mathrm{H}, \mathrm{s})$, four oxygenated methines at $\delta_{\mathrm{H}}$ $3.45(1 \mathrm{H}, \mathrm{m}), 3.57(1 \mathrm{H}, \mathrm{m}), 4.31(1 \mathrm{H}, \mathrm{d}, J=9.9 \mathrm{~Hz})$ and $5.18(1 \mathrm{H}, \mathrm{s})$, nitrogenated methines at at $\delta_{\mathrm{H}} 3.92(1 \mathrm{H}, \mathrm{m})$ and $3.76(1 \mathrm{H}, \mathrm{m})$, four aromatic protons at $\delta_{\mathrm{H}} 6.90(1 \mathrm{H}, \mathrm{d}, J=9.0 \mathrm{~Hz})$ and $7.00(1 \mathrm{H}, \mathrm{s})$ and 7.09 , amine hydrogen at $\delta_{\mathrm{H}} 6.47$ $(1 \mathrm{H}, \mathrm{t}, J=6.0 \mathrm{~Hz}), 8.14(1 \mathrm{H}, \mathrm{s})$ and $9.71(1 \mathrm{H}, \mathrm{s})$, two methanetriyl groups at $\delta_{\mathrm{H}}$ $1.77(1 \mathrm{H}, \mathrm{m}), 2.48(1 \mathrm{H}, \mathrm{m})$ and $2.68(1 \mathrm{H}, \mathrm{m})$ and three methanediyl groups at $\delta_{\mathrm{H}}$ $1.77(2 \mathrm{H}, \mathrm{m}), 2.44(1 \mathrm{H}, \mathrm{m}), 2.68(1 \mathrm{H}, \mathrm{m})$ and $2.74(1 \mathrm{H}, \mathrm{m}) \mathrm{ppm}$. The ${ }^{13} \mathrm{C}-\mathrm{NMR}$ spectrum exhibited 39 signals which were classified by the DEPT-135 and HMQC spectra as four methyl carbons at $\delta_{\mathrm{C}} 12.4(10-\mathrm{Me}), 12.6(2-\mathrm{Me}), 12.8$ $(8-\mathrm{Me})$ and $23.0(14-\mathrm{Me})$, three methyoxy carbons at $\delta_{\mathrm{C}} 56.0$ (29-OMe), 56.7 $(12-\mathrm{OMe})$ and $57.1(6-\mathrm{OMe})$, five olefin carbons at $\delta_{\mathrm{C}} 108.7(\mathrm{C}-19), \delta_{\mathrm{C}} 126.6$ $(\mathrm{C}-4), \delta_{\mathrm{C}} 107.0(\mathrm{C}-3), \delta_{\mathrm{C}} 133.8(\mathrm{C}-9)$ and $\delta_{\mathrm{C}} 135.8$ (C-5), five quaternary olefin carbons at $\delta_{\mathrm{C}} 108.5(\mathrm{C}-16), 132.8(\mathrm{C}-8), 135.0(\mathrm{C}-2), \delta_{\mathrm{C}} 141.4(\mathrm{C}-20)$ and 145.0 $(\mathrm{C}-17)$, four oxygenated methines at $\delta_{\mathrm{C}} 72.7(\mathrm{C}-11), 81.3(\mathrm{C}-6), 81.6(\mathrm{C}-12)$ and $81.8(\mathrm{C}-7)$, nitrogenated methines at $45.6(\mathrm{C}-22)$, four aromatic carbons at $\delta_{\mathrm{C}}$ 100.4 (C-28), 112.3 (C-30), 112.7 (C-31) and 123.4 (C-25), four quaternary aromatic carbons at $\delta_{\mathrm{C}} 111.0(\mathrm{C}-24), 127.3$ (C-27), $131.8(\mathrm{C}-26)$ and 154.3 (C-29), two methanetriyl carbons at $\delta_{\mathrm{C}} 28.6(\mathrm{C}-14)$ and 32.4 (C-10), three methanediyl carbons at $\delta_{\mathrm{C}} 25.8(\mathrm{C}-23), 34.5(\mathrm{C}-15)$ and $35.2(\mathrm{C}-13)$ and four carbonyl carbons at $\delta_{\mathrm{C}} 156.1\left(7-\mathrm{OCONH}_{2}\right), 168.4(\mathrm{C}-1), 180.6(\mathrm{C}-21)$ and $183.9(\mathrm{C}-18) \mathrm{ppm}$. The ${ }^{1} \mathrm{H}-{ }^{1} \mathrm{H}$ COSY spectrum revealed the connectivity in $\mathrm{CDCl}_{3}$ from $\mathrm{H}-3$ through $\mathrm{H}-4$; H-4 through $\mathrm{H}-3$ and H-5; H-5 through H-4 and H-6; H-6 through H-5 and $\mathrm{H}-7$; H-7 through $\mathrm{H}-6$; H-9 through $\mathrm{H}-10 ; \mathrm{H}-10$ through $\mathrm{H}-9,10-\mathrm{Me}$ and $\mathrm{H}-11 ; 10-\mathrm{Me}$ through $\mathrm{H}-10 ; \mathrm{H}-11$ through $\mathrm{H}-10$ and $\mathrm{H}-12 ; \mathrm{H}-12$ through $\mathrm{H}-11$ and $\mathrm{H}-13 ; \mathrm{H}-13$ through $\mathrm{H}-12 ; \mathrm{H}-14$ through 14-Me and 15; 14-Me through 
$\mathrm{H}-14$; $\mathrm{H}-15$ through $\mathrm{H}-14 ; \mathrm{H}-22$ through 22-NH and $\mathrm{H}-23$; $\mathrm{H}-23$ through $\mathrm{H}-22$; $\mathrm{H}-30$ through $\mathrm{H}-31$ and $\mathrm{H}-31$ through $\mathrm{H}-30$. The $\mathrm{HMBC}$ spectrum showed the following long-range correlations; $14-\mathrm{Me}\left(\delta_{\mathrm{H}} 0.94\right)$ to $\mathrm{C}-13\left(\delta_{\mathrm{C}} 35.2\right), \mathrm{C}-14\left(\delta_{\mathrm{C}}\right.$ $28.6)$ and $\mathrm{C}-15\left(\delta_{\mathrm{C}} 34.5\right) ; 10-\mathrm{Me}\left(\delta_{\mathrm{H}} 1.00\right)$ to $\mathrm{C}-9\left(\delta_{\mathrm{C}} 133.8\right), \mathrm{C}-10\left(\delta_{\mathrm{C}} 32.4\right)$ and C-11 $\left(\delta_{\mathrm{C}} 72.7\right) ; \mathrm{H}-13\left(\delta_{\mathrm{H}} 1.77\right)$ to $\mathrm{C}-11\left(\delta_{\mathrm{C}} 72.7\right), \mathrm{C}-12\left(\delta_{\mathrm{C}} 81.6\right)$ and C-14 $\left(\delta_{\mathrm{C}}\right.$ $28.6) ; \mathrm{H}-14\left(\delta_{\mathrm{H}} 1.77\right)$ to $\mathrm{C}-12\left(\delta_{\mathrm{C}} 81.6\right)$ and C-13 $\left(\delta_{\mathrm{C}} 35.2\right) ; 8-\mathrm{Me}\left(\delta_{\mathrm{H}} 1.80\right)$ to C-7 $\left(\delta_{\mathrm{C}} 81.8\right), \mathrm{C}-8\left(\delta_{\mathrm{C}} 132.8\right)$ and $\mathrm{C}-9\left(\delta_{\mathrm{C}} 133.8\right) ; 2-\mathrm{Me}\left(\delta_{\mathrm{H}} 2.02\right)$ to $\mathrm{C}-1\left(\delta_{\mathrm{C}} 168.4\right)$, C-2 $\left(\delta_{\mathrm{C}} 135.0\right)$ and C-3 $\left(\delta_{\mathrm{C}} 127.0\right) ; \mathrm{H}-15\left(\delta_{\mathrm{H}} 2.44,2.68\right)$ to C-13 $\left(\delta_{\mathrm{C}} 35.2\right), \mathrm{C}-14$ $\left(\delta_{\mathrm{C}} 28.6\right), 14-\mathrm{Me}\left(\delta_{\mathrm{C}} 23.0\right), \mathrm{C}-16\left(\delta_{\mathrm{C}} 108.5\right), \mathrm{C}-17\left(\delta_{\mathrm{C}} 145.0\right)$ and C-21 $\left(\delta_{\mathrm{C}} 180.6\right)$; $\mathrm{H}-10\left(\delta_{\mathrm{H}}[2.74] 2.73-2.78\right)$ to $\mathrm{C}-8\left(\delta_{\mathrm{C}} 132.8\right), \mathrm{C}-9\left(\delta_{\mathrm{C}} 133.8\right)$ and $10-\mathrm{Me}\left(\delta_{\mathrm{C}}\right.$ $12.4)$; H-23 $\left(\delta_{\mathrm{H}} 3.11\right)$ to $\mathrm{C}-22\left(\delta_{\mathrm{C}} 45.6\right), \mathrm{C}-24\left(\delta_{\mathrm{C}} 111.0\right)$ and $\mathrm{C}-25\left(\delta_{\mathrm{C}} 123.4\right)$; 6-OMe $\left(\delta_{\mathrm{H}} 3.27\right)$ to C-6 $\left(\delta_{\mathrm{C}} 81.3\right) ; 12-\mathrm{OMe}\left(\delta_{\mathrm{H}} 3.36\right)$ to C-12 $\left(\delta_{\mathrm{C}} 81.6\right) ; \mathrm{H}-12\left(\delta_{\mathrm{H}}\right.$ $3.45)$ to $\mathrm{C}-10\left(\delta_{\mathrm{C}} 32.4\right), \mathrm{C}-11\left(\delta_{\mathrm{C}} 72.7\right), 12-\mathrm{OMe}\left(\delta_{\mathrm{C}} 56.7\right)$ and $\mathrm{C}-14\left(\delta_{\mathrm{C}} 28.6\right)$; $\mathrm{H}-11\left(\delta_{\mathrm{H}}[3.57] 3.57-3.60\right)$ to C-9 $\left(\delta_{\mathrm{C}} 133.8\right), \mathrm{C}-10\left(\delta_{\mathrm{C}} 32.4\right), 10-\mathrm{Me}\left(\delta_{\mathrm{C}} 12.4\right)$ and C-12 $\left(\delta_{\mathrm{C}} 81.6\right) ; \mathrm{H}-22\left(\delta_{\mathrm{H}} 3.76,3.92\right)$ to C-23 $\left(\delta_{\mathrm{C}} 25.8\right)$ and C-24 $\left(\delta_{\mathrm{C}} 111.0\right)$; 29-OMe $\left(\delta_{\mathrm{H}} 3.87\right)$ to C-29 $\left(\delta_{\mathrm{C}} 154.3\right)$; H-6 $\left(\delta_{\mathrm{H}} 4.31\right)$ to $\mathrm{C}-4\left(\delta_{\mathrm{C}} 126.6\right)$ and 6-OMe $\left(\delta_{\mathrm{C}} 57.1\right)$; H-7 $\left(\delta_{\mathrm{H}} 5.18\right)$ to C-5 $\left(\delta_{\mathrm{C}} 135.8\right), 7-\mathrm{OCONH}_{2}\left(\delta_{\mathrm{C}} 156.1\right), \mathrm{C}-8\left(\delta_{\mathrm{C}} 132.8\right)$, $8-\mathrm{Me}\left(\delta_{\mathrm{C}} 12.8\right)$ and C-9 $\left(\delta_{\mathrm{C}} 133.8\right)$; H-5 $\left(\delta_{\mathrm{H}}[5.86] 5.85-5.87\right)$ to C-3 $\left(\delta_{\mathrm{C}} 127.0\right)$, C-4 $\left(\delta_{\mathrm{C}} 126.6\right), \mathrm{C}-6\left(\delta_{\mathrm{C}} 81.3\right)$ and C-7 $\left(\delta_{\mathrm{C}} 81.8\right)$; H-9 $\left(\delta_{\mathrm{H}} 5.89^{*}\right)$ to C-7 $\left(\delta_{\mathrm{C}} 81.8\right)$, $8-\mathrm{Me}\left(\delta_{\mathrm{C}} 12.8\right), 10-\mathrm{Me}\left(\delta_{\mathrm{C}} 12.4\right)$ and $\mathrm{C}-11\left(\delta_{\mathrm{C}} 72.7\right) ; 22-\mathrm{NH}\left(\delta_{\mathrm{H}} 6.47\right)$ to C-16 $\left(\delta_{\mathrm{C}}\right.$ $108.5), \mathrm{C}-18\left(\delta_{\mathrm{C}} 183.9\right), \mathrm{C}-22\left(\delta_{\mathrm{C}} 45.6\right)$ and C-23 $\left(\delta_{\mathrm{C}} 25.8\right) ; \mathrm{H}-4\left(\delta_{\mathrm{H}} 6.57\right)$ to $\mathrm{C}-2$ $\left(\delta_{\mathrm{C}} 135.0\right), \mathrm{C}-3\left(\delta_{\mathrm{C}} 127.0\right)$ and C-5 $\left(\delta_{\mathrm{C}} 135.8\right) ; \mathrm{H}-31\left(\delta_{\mathrm{H}} 6.90\right)$ to C-26 $\left(\delta_{\mathrm{C}} 131.8\right)$, C-27 $\left(\delta_{\mathrm{C}} 127.3\right)$ and C-29 $\left(\delta_{\mathrm{C}} 154.3\right) ; \mathrm{H}-3\left(\delta_{\mathrm{H}} 6.95\right)$ to C-1 $\left(\delta_{\mathrm{C}} 168.4\right), \mathrm{C}-2\left(\delta_{\mathrm{C}}\right.$ $135.0), 2-\mathrm{Me}\left(\delta_{\mathrm{C}} 12.6\right), \mathrm{C}-4\left(\delta_{\mathrm{C}} 126.6\right)$ and C-5 $\left(\delta_{\mathrm{C}} 135.8\right) ; \mathrm{H}-28\left(\delta_{\mathrm{H}} 7.00\right)$ to C-24 $\left(\delta_{\mathrm{C}} 111.0\right), \mathrm{C}-26\left(\delta_{\mathrm{C}} 131.8\right), \mathrm{C}-29\left(\delta_{\mathrm{C}} 154.3\right)$ and C-30 $\left(\delta_{\mathrm{C}} 112.3\right) ; \mathrm{H}-25\left(\delta_{\mathrm{H}} 7.09^{*}\right)$ to C-23 $\left(\delta_{\mathrm{C}} 25.8\right), \mathrm{C}-24\left(\delta_{\mathrm{C}} 111.0\right), \mathrm{C}-26\left(\delta_{\mathrm{C}} 131.8\right)$ and C-27 $\left(\delta_{\mathrm{C}} 127.3\right) ; \mathrm{H}-19\left(\delta_{\mathrm{H}}\right.$ $7.24)$ to $\mathrm{C}-17\left(\delta_{\mathrm{C}} 145.0\right)$ and $\mathrm{C}-21\left(\delta_{\mathrm{C}} 180.6\right) ; \mathrm{H}-30\left(\delta_{\mathrm{H}} 7.29\right)$ to C-29 $\left(\delta_{\mathrm{C}} 154.3\right)$; $25-\mathrm{NH}\left(\delta_{\mathrm{H}} 8.14\right)$ to $\mathrm{C}-24\left(\delta_{\mathrm{C}} 111.0\right), \mathrm{C}-25\left(\delta_{\mathrm{C}} 123.4\right), \mathrm{C}-26\left(\delta_{\mathrm{C}} 131.8\right)$ and C-27 $\left(\delta_{\mathrm{C}} 127.3\right) ; 1-\mathrm{NH}\left(\delta_{\mathrm{H}} 9.17\right)$ to $\mathrm{C}-1\left(\delta_{\mathrm{C}} 168.4\right), \mathrm{C}-19\left(\delta_{\mathrm{C}} 108.7\right)$ and C-21 $\left(\delta_{\mathrm{C}} 180.6\right)$ (Table 3).

Table 2. Comparison of the spectral data of the compound 2 and compound 3.

\begin{tabular}{ccccc}
\hline No. & $\delta_{\mathrm{C}}$ compound 2 & $\boldsymbol{\delta}_{\mathrm{C}}$ compound 3 & $\boldsymbol{\delta}_{\mathrm{H}}$ compound 2 & $\boldsymbol{\delta}_{\mathrm{H}}$ compound 3 \\
\hline 1 & $168.4 \mathrm{C}$ & $168.4 \mathrm{C}$ & - & - \\
2 & $135.0 \mathrm{C}$ & $135.0 \mathrm{C}$ & - & $2.02 \mathrm{~s}$ \\
$2-\mathrm{Me}$ & $12.5 \mathrm{CH}_{3}$ & $12.6 \mathrm{CH}_{3}$ & $2.02 \mathrm{~s}$ & $6.95 \mathrm{~d}(11.4)$ \\
3 & $126.9 \mathrm{CH}$ & $127.0 \mathrm{CH}$ & $6.95 \mathrm{~d}(12)$ & $6.57 \mathrm{t}(11.4)$ \\
4 & $126.5 \mathrm{CH}$ & $126.6 \mathrm{CH}$ & $6.58 \mathrm{t}(12)$ & $5.86 \mathrm{~m}$ \\
5 & $135.8 \mathrm{CH}$ & $138.7 \mathrm{CH}$ & $5.86 \mathrm{~m}$ & $4.31 \mathrm{~d}(9.9)$ \\
6 & $81.2 \mathrm{CH}$ & $81.3 \mathrm{CH}$ & $4.30 \mathrm{~d}(9.9)$ & $3.27 \mathrm{~s}$ \\
7
\end{tabular}




\section{Continued}

\begin{tabular}{|c|c|c|c|c|}
\hline 7-OCONH & $156.1 \mathrm{C}$ & $156.1 \mathrm{C}$ & - & - \\
\hline 8 & $132.7 \mathrm{C}$ & $132.8 \mathrm{C}$ & - & - \\
\hline 8-Me & $12.7 \mathrm{CH}_{3}$ & $12.8 \mathrm{CH}_{3}$ & $1.80 \mathrm{~s}$ & $1.80 \mathrm{~s}$ \\
\hline 9 & $133.8 \mathrm{CH}$ & $133.8 \mathrm{CH}$ & $5.89 \mathrm{~m}$ & 5.89 \\
\hline 10 & $32.3 \mathrm{CH}$ & $32.4 \mathrm{CH}$ & $2.74 \mathrm{~m}$ & $2.74 \mathrm{~m}$ \\
\hline $10-\mathrm{Me}$ & $12.3 \mathrm{CH}_{3}$ & $12.4 \mathrm{CH}_{3}$ & $0.99 \mathrm{~d}(6.9)$ & $1.00 \mathrm{~d}(6.9)$ \\
\hline 11 & $72.6 \mathrm{CH}$ & $72.7 \mathrm{CH}$ & $3.57 \mathrm{~d}(9)$ & $3.57 \mathrm{~m}$ \\
\hline $11-\mathrm{OH}$ & - & - & - & - \\
\hline 12 & $81.5 \mathrm{CH}$ & $81.6 \mathrm{CH}$ & $3.45 \mathrm{~m}$ & $3.45 \mathrm{~m}$ \\
\hline $12-\mathrm{OMe}$ & $56.7 \mathrm{OCH}_{3}$ & $56.7 \mathrm{OCH}_{3}$ & $3.36 \mathrm{~s}$ & $3.36 \mathrm{~s}$ \\
\hline 13 & $35.0 \mathrm{CH}_{2}$ & $35.2 \mathrm{CH}_{2}$ & $1.77 \mathrm{~m}$ & $1.77 \mathrm{~m}$ \\
\hline 14 & $28.5 \mathrm{CH}$ & $28.6 \mathrm{CH}$ & $1.77 \mathrm{~m}$ & $1.77 \mathrm{~m}$ \\
\hline $14-\mathrm{Me}$ & $22.8 \mathrm{CH}_{3}$ & $23.0 \mathrm{CH}_{3}$ & $0.93 \mathrm{~d}(6.3)$ & $0.94 \mathrm{~d}(6.3)$ \\
\hline $\begin{array}{l}15 \mathrm{a} \\
15 \mathrm{~b}\end{array}$ & $34.4 \mathrm{CH}_{2}$ & $34.5 \mathrm{CH}_{2}$ & $\begin{array}{l}2.70 \\
2.40\end{array}$ & $\begin{array}{l}2.68 \mathrm{~m}(12.5,9.9) \\
2.44 \mathrm{~m}(12.5,4.8)\end{array}$ \\
\hline 16 & $108.6 \mathrm{C}$ & $108.5 \mathrm{C}$ & - & - \\
\hline 17 & $144.9 \mathrm{C}$ & $145.0 \mathrm{C}$ & - & - \\
\hline 17-OMe & - & - & - & - \\
\hline 18 & $183.8 \mathrm{C}$ & $183.9 \mathrm{C}$ & - & - \\
\hline 19 & $108.7 \mathrm{CH}$ & $108.7 \mathrm{CH}$ & $7.24 \mathrm{~s}$ & $7.24 \mathrm{~s}$ \\
\hline 20 & $141.4 \mathrm{C}$ & $141.4 \mathrm{C}$ & - & - \\
\hline 21 & $180.5 \mathrm{C}$ & $180.6 \mathrm{C}$ & - & - \\
\hline $\begin{array}{l}22 \mathrm{a} \\
22 \mathrm{~b}\end{array}$ & $45.7 \mathrm{CH}_{2}$ & $45.6 \mathrm{CH}_{2}$ & $\begin{array}{l}3.91 \mathrm{~m} \\
3.77 \mathrm{~m}\end{array}$ & $\begin{array}{l}3.92 \mathrm{~m} \\
3.76 \mathrm{~m}\end{array}$ \\
\hline 23 & $25.75 \mathrm{CH}_{2}$ & $25.8 \mathrm{CH}_{2}$ & $3.15 \mathrm{t}(6.6)$ & $3.11 \mathrm{t}(6.6)$ \\
\hline 24 & $111.3 \mathrm{C}$ & $111.0 \mathrm{C}$ & - & - \\
\hline 25 & $122.5 \mathrm{CH}$ & $123.4 \mathrm{CH}$ & $7.13 \mathrm{~m}$ & 7.09 \\
\hline 26 & $136.6 \mathrm{C}$ & $131.8 \mathrm{C}$ & - & - \\
\hline 27 & $126.8 \mathrm{C}$ & $127.3 \mathrm{C}$ & - & - \\
\hline 28 & $111.5 \mathrm{CH}$ & $100.4 \mathrm{CH}$ & $7.40 \mathrm{~d}(7.8)$ & $7.00 \mathrm{~s}$ \\
\hline 29 & $119.8 \mathrm{CH}$ & $154.3 \mathrm{C}$ & $7.13 \mathrm{~m}$ & - \\
\hline $29-\mathrm{OMe}$ & - & $56.0 \mathrm{OCH}_{3}$ & - & $3.87 \mathrm{~s}$ \\
\hline 30 & $125.6 \mathrm{CH}$ & $112.3 \mathrm{CH}$ & $7.15 \mathrm{~m}$ & $7.29 \mathrm{~d}(9)$ \\
\hline 31 & $118.5 \mathrm{CH}$ & $112.7 \mathrm{CH}$ & $7.60 \mathrm{~d}(7.8)$ & $6.90 \mathrm{~d}(9)$ \\
\hline $1-\mathrm{NH}$ & - & - & $9.17 \mathrm{~s}$ & $9.17 \mathrm{~s}$ \\
\hline $22-\mathrm{NH}$ & - & - & 6.47 brs $(6.0)$ & $6.47 \mathrm{t}(6.0)$ \\
\hline $25-\mathrm{NH}$ & - & - & $8.25 \mathrm{~s}$ & $8.14 \mathrm{~s}$ \\
\hline
\end{tabular}

${ }^{1} \mathrm{H}$ and ${ }^{13} \mathrm{C}-\mathrm{NMR}$ assignments for the compound 2 and compound 3; $\left[{ }^{1} \mathrm{H}(300 \mathrm{MHz}),{ }^{13} \mathrm{C}-\mathrm{NMR}(75 \mathrm{MHz}), \mathrm{CDCl}_{3}, J=\mathrm{Hz}\right]$. 
Table 3. Comparison of the spectral data of the compound 3 and compound 1.

\begin{tabular}{|c|c|c|c|c|c|c|}
\hline No. & $\delta_{\mathrm{C}}$ compound 3 & $\delta_{\mathrm{C}}$ compound 1 & $\delta_{\mathrm{H}}$ compound 3 & $\delta_{\mathrm{H}}$ compound 1 & $\mathrm{HMBC}(\mathrm{H} \rightarrow \mathrm{C})$ & COSY \\
\hline 1 & $168.4 \mathrm{C}$ & $169.7 \mathrm{C}$ & - & - & - & - \\
\hline 2 & $135.0 \mathrm{C}$ & $133.2 \mathrm{C}$ & - & - & - & - \\
\hline 2-Me & $12.6 \mathrm{CH}_{3}$ & $12.8 \mathrm{CH}_{3}$ & $2.02 \mathrm{~s}$ & $1.93 \mathrm{~s}$ & $1,2,3$ & - \\
\hline 3 & $127.0 \mathrm{CH}$ & $128.7 \mathrm{CH}$ & $6.95 \mathrm{~d}(11.4)$ & $6.95 \mathrm{~d}$ & $1,2,2-\mathrm{Me}, 4,5$ & 4 \\
\hline 4 & $126.6 \mathrm{CH}$ & $126.3 \mathrm{CH}$ & $6.57 \mathrm{t}(11.4)$ & $6.58 \mathrm{t}$ & $2,3,5$ & 3,5 \\
\hline 5 & $135.8 \mathrm{CH}$ & $138.7 \mathrm{CH}$ & $5.86 \mathrm{~m}$ & 5.81 brs & $3,4,6,7$ & 4,6 \\
\hline 6 & $81.3 \mathrm{CH}$ & $82.3 \mathrm{CH}$ & $4.31 \mathrm{~d}(9.9)$ & $4.36 \mathrm{~d}(7.6)$ & $4,6-\mathrm{OMe}$ & 5,7 \\
\hline 6-OMe & $57.1 \mathrm{CH}_{3}$ & $57.1 \mathrm{CH}_{3}$ & $3.27 \mathrm{~s}$ & $3.24 \mathrm{~s}$ & 6 & - \\
\hline 7 & $81.8 \mathrm{CH}$ & $81.1 \mathrm{CH}$ & $5.18 \mathrm{~s}$ & 4.88 brs & $5,7-\mathrm{OCONH}_{2}, 8,8-\mathrm{Me}, 9$ & 6 \\
\hline 7-OCONH${ }_{2}$ & $156.1 \mathrm{C}$ & $156.6 \mathrm{C}$ & - & - & - & - \\
\hline 8 & $132.8 \mathrm{C}$ & $129.1 \mathrm{C}$ & - & - & - & - \\
\hline 8-Me & $12.8 \mathrm{CH}_{3}$ & $13.0 \mathrm{CH}_{3}$ & $1.80 \mathrm{~s}$ & $1.62 \mathrm{~s}$ & $7,8,9$ & - \\
\hline 9 & $133.8 \mathrm{CH}$ & $132.4 \mathrm{CH}$ & $5.89^{*}$ & $5.50 \mathrm{~d}(8.5)$ & 7, 8-Me, $10-\mathrm{Me}, 11$ & 10 \\
\hline 10 & $32.4 \mathrm{CH}$ & $32.6 \mathrm{CH}$ & $2.74 \mathrm{~m}$ & 2.56 & $8,9,10-\mathrm{Me}$ & $9,10-\mathrm{Me}, 11$ \\
\hline $10-\mathrm{Me}$ & $12.4 \mathrm{CH}_{3}$ & $13.4 \mathrm{CH}_{3}$ & $1.00 \mathrm{~d}(6.9)$ & $0.75 \mathrm{~d}(6.8)$ & $9,10,11$ & 10 \\
\hline 11 & $72.7 \mathrm{CH}$ & $72.4 \mathrm{CH}$ & $3.57 \mathrm{~m}$ & $3.09 \mathrm{brs}$ & $9,10,10-\mathrm{Me}, 12$ & 10,12 \\
\hline $11-\mathrm{OH}$ & - & - & - & - & - & - \\
\hline 12 & $81.6 \mathrm{CH}$ & $80.7 \mathrm{CH}$ & $3.45 \mathrm{~m}$ & $3.09 \mathrm{brs}$ & $10,11,12-\mathrm{OMe}, 14$ & 11,13 \\
\hline $12-\mathrm{OMe}$ & $56.7 \mathrm{OCH}_{3}$ & $56.5 \mathrm{CH}_{3}$ & $3.36 \mathrm{~s}$ & $3.23 \mathrm{~s}$ & 12 & - \\
\hline 13 & $35.2 \mathrm{CH}_{2}$ & $31.3 \mathrm{CH}_{2}$ & $1.77 \mathrm{~m}$ & $1.45 \mathrm{brs}$ & $11,12,14$ & 12 \\
\hline 14 & $28.6 \mathrm{CH}$ & $27.1 \mathrm{CH}$ & $1.77 \mathrm{~m}$ & $1.93 \mathrm{~s}$ & 12,13 & $14-\mathrm{Me}, 15 \mathrm{~b}$ \\
\hline $14-\mathrm{Me}$ & $23.0 \mathrm{CH}_{3}$ & $23.9 \mathrm{CH}_{3}$ & $0.94 \mathrm{~d}(6.3)$ & 0.97 brs & $13,14,15$ & 14 \\
\hline $15 \mathrm{a}$ & \multirow{2}{*}{$34.5 \mathrm{CH}_{2}$} & \multirow{2}{*}{$32.2 \mathrm{CH}_{2}$} & $2.68 \mathrm{~m}$ & $2.43 \mathrm{dd}(12.5,9.9)$ & $13,14,14-\mathrm{Me}, 16,17,21$ & $15 b$ \\
\hline $15 b$ & & & $2.44 \mathrm{~m}$ & $2.18 \mathrm{dd}(12.5,4.8)$ & $14,16,17,21$ & $14,15 \mathrm{a}$ \\
\hline 16 & $108.5 \mathrm{C}$ & $128.7 \mathrm{C}$ & - & - & - & - \\
\hline 17 & $145.0 \mathrm{C}$ & $156.9 \mathrm{C}$ & - & - & - & - \\
\hline 17-OMe & - & $61.6 \mathrm{CH}_{3}$ & - & $3.96 \mathrm{~s}$ & - & - \\
\hline 18 & $183.9 \mathrm{C}$ & $184.3 \mathrm{C}$ & - & - & - & - \\
\hline 19 & $108.7 \mathrm{CH}$ & $111.3 \mathrm{CH}$ & $7.24 \mathrm{~s}$ & $7.04 \mathrm{~s}$ & 17,21 & - \\
\hline 20 & $141.4 \mathrm{C}$ & $140.1 \mathrm{C}$ & - & - & - & - \\
\hline 21 & $180.6 \mathrm{C}$ & $183.6 \mathrm{C}$ & - & - & - & - \\
\hline $22 \mathrm{a}$ & \multirow{2}{*}{$45.6 \mathrm{CH}_{2}$} & \multirow{2}{*}{-} & $3.92 \mathrm{~m}$ & - & 23,24 & $22 \mathrm{~b}, 22-\mathrm{NH}, 23$ \\
\hline $22 \mathrm{~b}$ & & & $3.76 \mathrm{~m}$ & - & 23,24 & $22 \mathrm{a}, 22-\mathrm{NH}, 23$ \\
\hline 23 & $25.8 \mathrm{CH}_{2}$ & - & $3.11 \mathrm{t}(6.6)$ & - & $22,24,25$ & $22 \mathrm{a}, 22 \mathrm{~b}$ \\
\hline 24 & $111.0 \mathrm{C}$ & - & - & - & - & - \\
\hline 25 & $123.4 \mathrm{CH}$ & - & $7.09^{*}$ & - & $23,24,26,27$ & - \\
\hline
\end{tabular}


Continued

\begin{tabular}{|c|c|c|c|c|c|c|}
\hline 26 & $131.8 \mathrm{C}$ & - & - & - & - & - \\
\hline 27 & $127.3 \mathrm{C}$ & - & - & - & - & - \\
\hline 28 & $100.4 \mathrm{CH}$ & - & $7.00 \mathrm{~s}$ & - & $24,26,29,30$ & - \\
\hline 29 & $154.3 \mathrm{C}$ & - & - & - & - & - \\
\hline 29-OMe & $56.0 \mathrm{OCH}_{3}$ & - & $3.87 \mathrm{~s}$ & - & 29 & - \\
\hline 30 & $112.3 \mathrm{CH}$ & - & $7.29 \mathrm{~d}(9)$ & - & 29 & 31 \\
\hline 31 & $112.7 \mathrm{CH}$ & - & $6.90 \mathrm{~d}(9)$ & - & $26,27,29$ & 30 \\
\hline $1-\mathrm{NH}$ & - & - & $9.17 \mathrm{~s}$ & $9.18, \mathrm{NH}$, brs & $1,19,21$ & - \\
\hline $22-\mathrm{NH}$ & - & - & $6.47 \mathrm{t}(6.0)$ & - & $16,18,22,23$ & $22 a, 22 b$ \\
\hline $25-\mathrm{NH}$ & - & - & $8.14 \mathrm{~s}$ & - & $24,25,26,27$ & 25 \\
\hline
\end{tabular}

${ }^{1} \mathrm{H}$ and ${ }^{13} \mathrm{C}$-NMR assignments for compound $3\left[{ }^{1} \mathrm{H}(300 \mathrm{MHz}),{ }^{13} \mathrm{C}-\mathrm{NMR}(75 \mathrm{MHz}), \mathrm{DMSO}-d 6, J=\mathrm{Hz}\right]$; compound $\mathbf{1}\left[{ }^{1} \mathrm{H}(400 \mathrm{MHz}),{ }^{13} \mathrm{C}-\mathrm{NMR}(100 \mathrm{MHz})\right.$, DMSO- $d 6, J=\mathrm{Hz}] .{ }^{*}$ refer to overlapped proton resonances.

\subsection{Effects of Geldanamycin Derivatives on Cell Viability in RAW 264.7 Cells}

In this study, geldanamycin and its derivatives at concentrations of 10 and 40 $\mu \mathrm{g} / \mathrm{ml}$ caused a significant reduction in cell viability $(p<0.05)$. However, These compounds at concentrations of 1 to $5 \mu \mathrm{g} / \mathrm{ml}$ did not show any cytotoxic activity in MTT assays. In detail, the cell viability in RAW 264.7 cells which were incubated with compound 1 at concentrations of $1,2.5,5,10,20$ and $40 \mu \mathrm{g} / \mathrm{ml}$ for 24 $\mathrm{h}$ were $97.42 \% \pm 6.68 \%, 94.71 \% \pm 5.33 \%, 91.06 \% \pm 4.25 \%, 73.58 \% \pm 6.91 \%$, $56.44 \% \pm 4.56 \%$, and $45.92 \% \pm 4.37 \%$, respectively, while the cell viability of compound 2 at different concentrations were $102.18 \% \pm 4.63 \%, 101.73 \% \pm$ $4.49 \%, 98.84 \% \pm 5.21 \%, 83.13 \% \pm 4.67 \%, 68.39 \% \pm 5.87 \%$, and $58.74 \% \pm 5.06 \%$, respectively, and the cell viability of compound 3 at different concentrations were $101.94 \% \pm 4.38 \%, 100.57 \% \pm 3.67 \%, 97.26 \% \pm 5.31 \%, 84.51 \% \pm 5.06 \%$, $66.25 \% \pm 6.76 \%$, and $60.65 \% \pm 6.72 \%$ of the control group treated with LPS only, respectively, while the cell viability of the blank group treated with media only was $102.73 \% \pm 3.66 \%$ (Figure 3). Therefore, the non-toxic concentrations of up to $5 \mu \mathrm{g} / \mathrm{ml}$ were chosen for subsequent experiments.

\subsection{Effects of Geldanamycin Derivatives on NO and $\mathrm{PGE}_{2}$ Production in LPS-Induced RAW 264.7 Cells}

LSP caused a significant increase in $\mathrm{NO}$ and $\mathrm{PGE}_{2}$ production when compared with the blank control, geldanamycin and its derivatives at concentrations of 1 , 2.5 and $5 \mu \mathrm{g} / \mathrm{ml}$ caused a significant reduction in $\mathrm{NO}$ and $\mathrm{PGE}_{2}$ production when compared with LPS-induced control group $(p<0.05)$. In detail, the production of NO in LPS-induced RAW 264.7 incubated with compound 1 at concentrations of $1,2.5$ and $5 \mu \mathrm{g} / \mathrm{ml}$ for $24 \mathrm{~h}$ were $48.72 \pm 7.43,36.51 \pm 5.84$ and $20.28 \pm 4.66 \mu \mathrm{M}$, respectively, the production of NO in LPS-induced RAW 264.7 incubated with compound 2 at different concentrations were $34.59 \pm 6.83,26.56$ \pm 6.15 and $17.45 \pm 4.86 \mu \mathrm{M}$, respectively, and with compound 3 at different 
concentrations were $31.76 \pm 5.87,22.52 \pm 5.63$ and $15.47 \pm 4.55 \mu \mathrm{M}$, respectively, while the production of NO in the group treated with LPS only was $52.64 \pm 6.11$ $\mu \mathrm{M}$. The production of $\mathrm{PGE}_{2}$ in LPS-induced RAW 264.7 incubated with compound 1 at concentrations of $1,2.5$ and $5 \mu \mathrm{g} / \mathrm{ml}$ for $24 \mathrm{~h}$ were $36.75 \pm 6.05,26.67$ \pm 6.81 and $20.87 \pm 3.70 \mathrm{ng} / \mathrm{ml}$, respectively, the production of $\mathrm{PGE}_{2}$ in LPS-induced RAW 264.7 incubated with compound 2 at different concentrations were $30.74 \pm 6.05,20.62 \pm 6.23$ and $15.77 \pm 3.48 \mathrm{ng} / \mathrm{ml}$, respectively, and with compound 3 at different concentrations were $27.06 \pm 5.53,17.61 \pm 4.39$ and $13.27 \pm 3.10 \mathrm{ng} / \mathrm{ml}$, respectively, while the production of $\mathrm{PGE}_{2}$ in the group treated with LPS only was $51.75 \pm 6.56 \mathrm{ng} / \mathrm{ml}$. Therefore, the inhibitory levels of geldanamycin and its derivatives on $\mathrm{NO}$ and $\mathrm{PGE}_{2}$ production also showed a dose-dependent manner (Figure $4(\mathrm{NO})$ and Figure $5\left(\mathrm{PGE}_{2}\right)$ ).

\subsection{Effects of Geldanamycin Derivatives on Pro-Inflammatory Cytokine Production in LPS-Induced RAW 264.7 Cells}

In this study, data showed that geldanamycin and its derivatives decreased production of pro-inflammatory cytokines such as TNF- $\alpha$, IL-1 $\beta$, IL-6 and IL-10 in LPS-induced RAW 264.7 cells $(p<0.05)$ (Figure 6-9). Treatment with LPS alone in RAW 264.7 cells resulted in a significant increase of pro-inflammatory cytokine productions compared with the blank control group. The detailed results of this assay are as follows: TNF- $\alpha$ productions in LPS-induced RAW 264.7 cells incubated with compound 1 at concentrations of $1,2.5$ and $5 \mu \mathrm{g} / \mathrm{ml}$ for $24 \mathrm{~h}$ were $36.56 \pm 5.51,22.79 \pm 4.80$ and $14.73 \pm 4.52 \mathrm{ng} / \mathrm{ml}$, respectively,

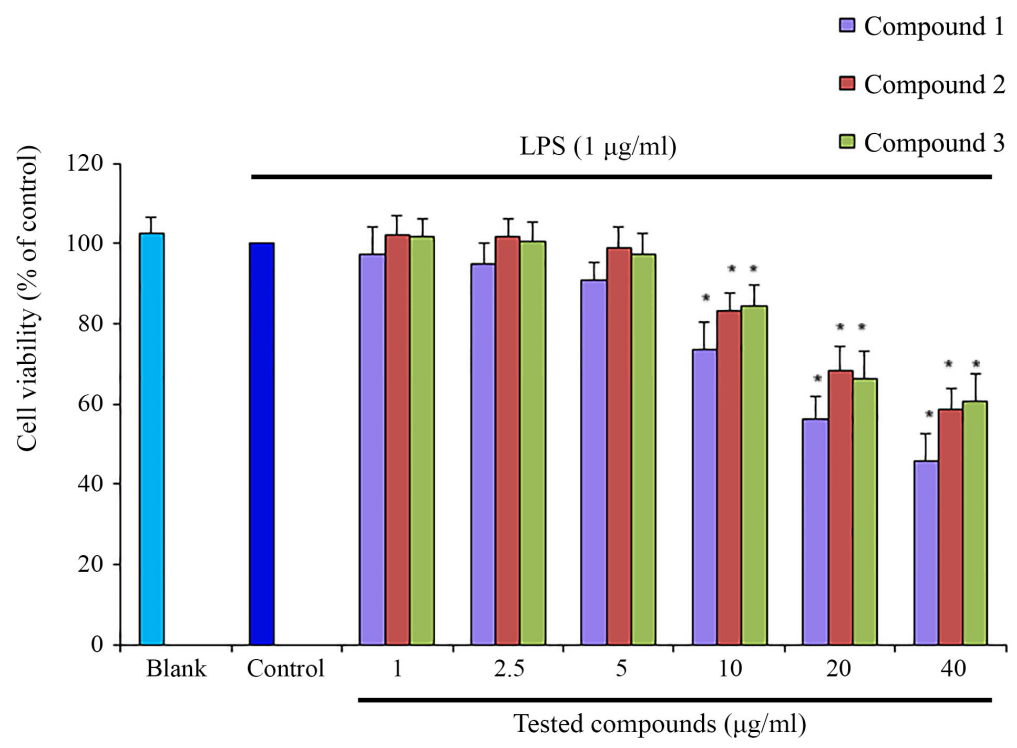

Figure 3. Effects of geldanamycin and its derivatives on cell viability in LPS-induced RAW 264.7 macrophage cells. RAW 264.7 cells were cultured with increasing concentrations $(1-40 \mu \mathrm{g} / \mathrm{ml})$ of geldanamycin and its derivatives in the presence of LPS $(1 \mu \mathrm{g} / \mathrm{ml})$ for $24 \mathrm{~h}$. Cell viability was tested by MTT assays. The values are the means of at least three determinations \pm SEM. Probability level (Tukey's post-hoc test): ${ }^{\star} p<0.05$ among tested groups. 


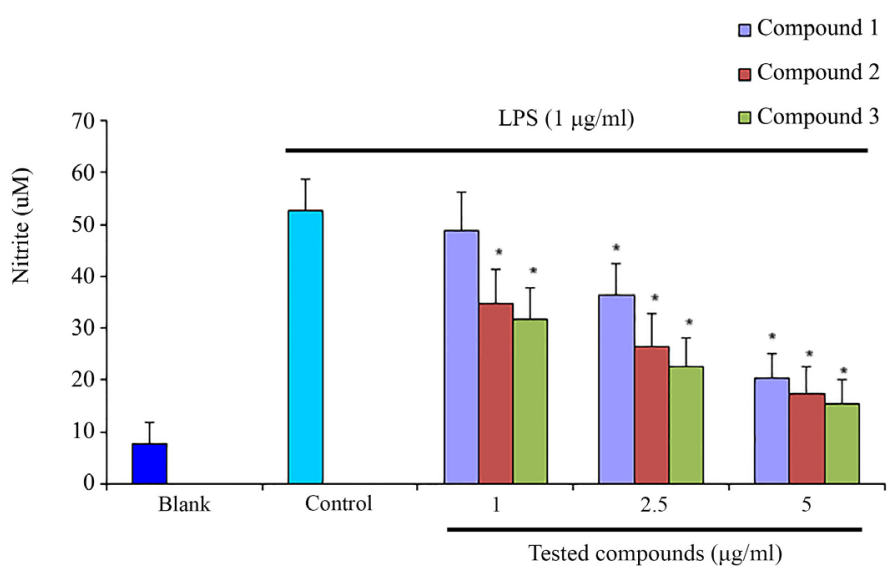

Figure 4. Evaluation of nitrite production by RAW 264.7 cells stimulated for $24 \mathrm{~h}$ with LPS alone or in combination with increasing concentrations $(1-5 \mu \mathrm{g} / \mathrm{ml})$ of geldanamycin and its derivatives. The values are the means of at least three determinations \pm SEM. Probability level (Student's $t$-test): ${ }^{\star} p<0.05 v s$. LPS-treated group.

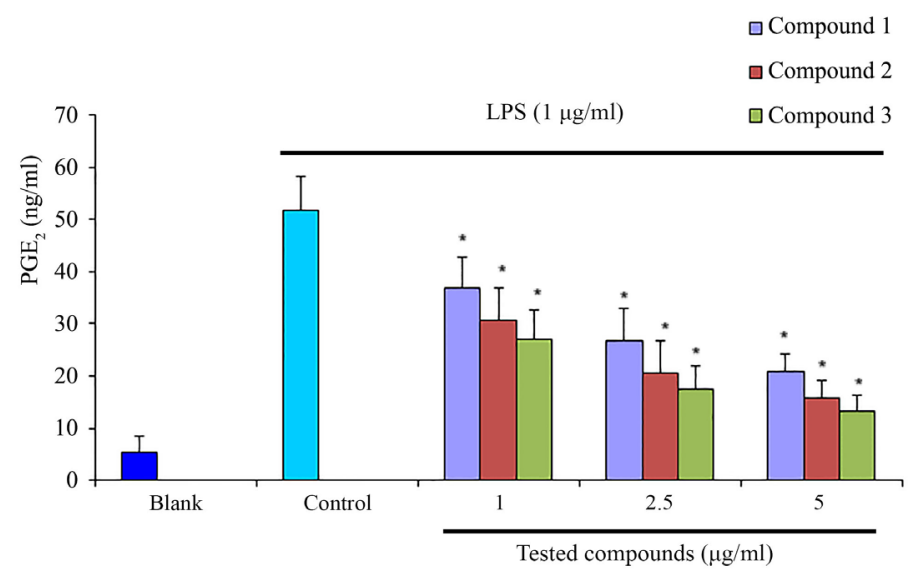

Figure 5. Effect of geldanamycin and its derivatives on $\mathrm{PGE}_{2}$ production in LPS-induced RAW 264.7 macrophage for $24 \mathrm{~h}$. The values are the means of at least three determinations \pm SEM. Probability level (Student's $t$-test): ${ }^{\star} p<0.05$ vs. LPS-treated group.

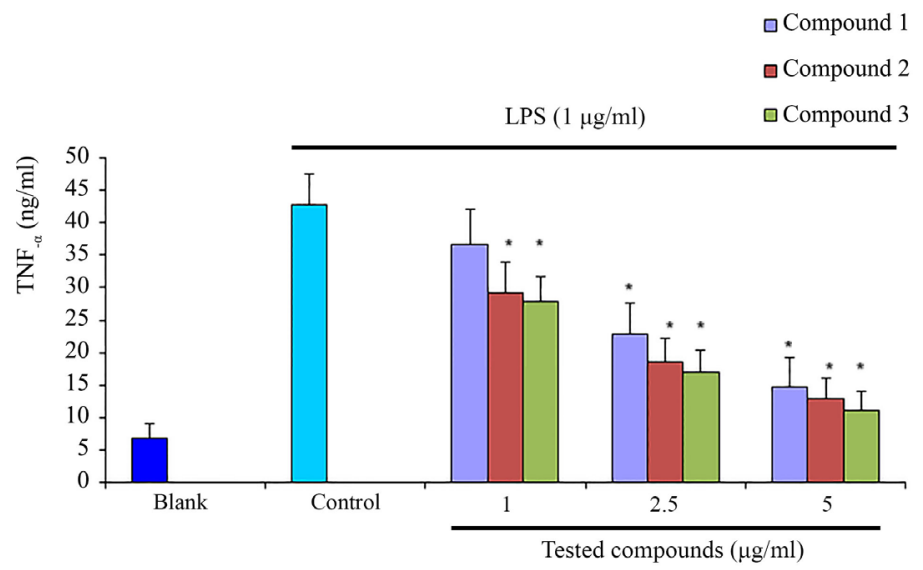

Figure 6. Effect of geldanamycin and its derivatives on LPS-induced TNF- $\alpha$ production by RAW 264.7 cells. The values are the means of at least three determinations \pm SEM. Probability level (Student's $t$-test): ${ }^{\star} p<0.05$ vs. LPS-treated group. 


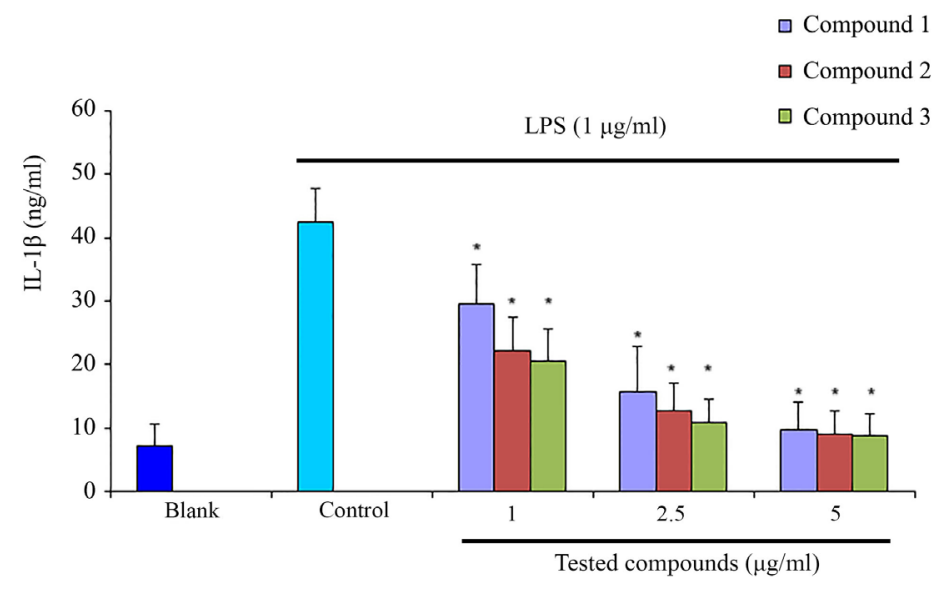

Figure 7. Effect of geldanamycin and its derivatives on LPS-induced IL-1 $\beta$ production by RAW 264.7 cells. The values are the means of at least three determinations \pm SEM. Probability level (Student's $t$-test): ${ }^{*} p<0.05$ vs. LPS-treated group.

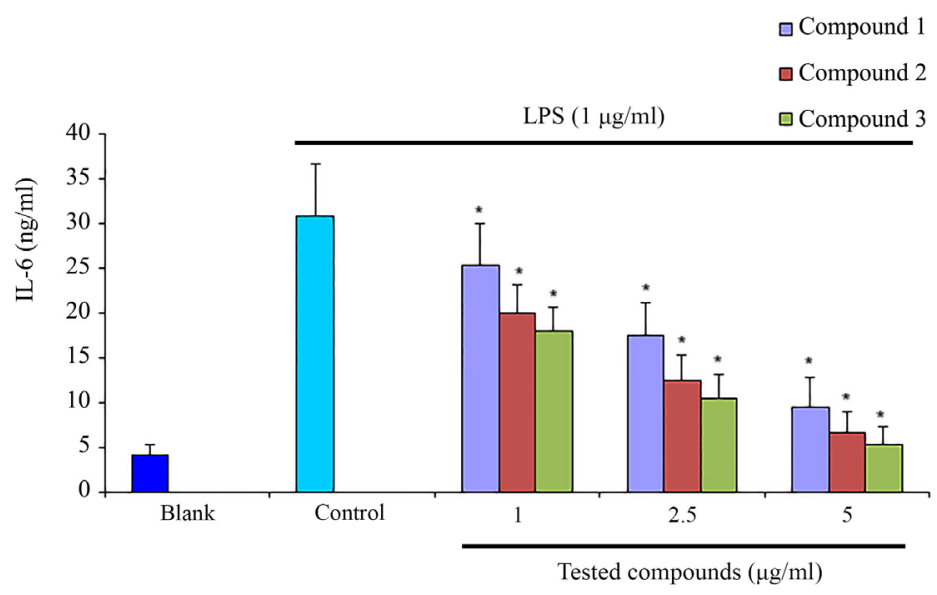

Figure 8. Effect of geldanamycin and its derivatives on LPS-induced IL-6 production by RAW 264.7 cells. The values are the means of at least three determinations \pm SEM. Probability level (Student's $t$-test): ${ }^{*} p<0.05$ vs. LPS-treated group.

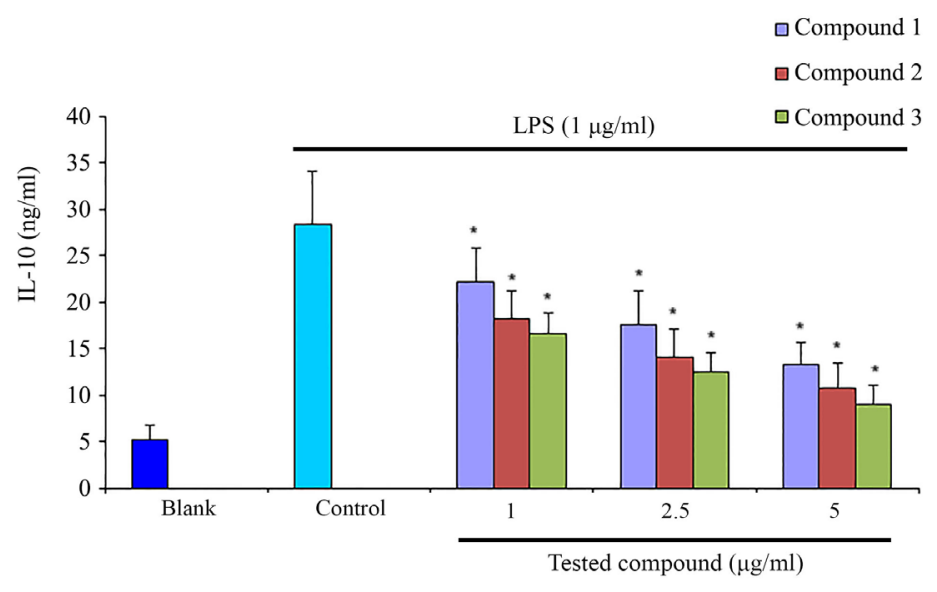

Figure 9. Effect of geldanamycin and its derivatives on LPS-induced IL-10 production by RAW 264.7 cells. The values are the means of at least three determinations \pm SEM. Probability level (Student's $t$-test): ${ }^{*} p<0.05 v s$. LPS-treated group. 
TNF- $\alpha$ productions in LPS-induced RAW 264.7 incubated with compound 2 at different concentrations were $29.28 \pm 4.61,18.47 \pm 3.69$ and $12.82 \pm 3.17 \mathrm{ng} / \mathrm{ml}$, respectively, and TNF- $\alpha$ productions in LPS-induced RAW 264.7 incubated with compound 3 at different concentrations were $27.78 \pm 3.95,16.88 \pm 3.47$ and $11.21 \pm 2.87 \mathrm{ng} / \mathrm{ml}$, respectively while the production of TNF- $\alpha$ in the group treated with LPS only was $42.73 \pm 4.78 \mathrm{ng} / \mathrm{ml}$, IL- $1 \beta$ productions in LPS-induced RAW 264.7 cells incubated with compound 1 at different concentrations were $29.57 \pm 6.28,15.65 \pm 7.26$ and $9.62 \pm 4.58 \mathrm{ng} / \mathrm{ml}$, respectively, IL- $1 \beta$ productions in LPS-induced RAW 264.7 cells incubated with compound 2 at different concentrations were $22.16 \pm 5.43,12.77 \pm 4.35$ and $9.08 \pm 3.57 \mathrm{ng} / \mathrm{ml}$, respectively, and IL-1 $\beta$ productions in LPS-induced RAW 264.7 cells incubated with compound 3 at different concentrations were $20.67 \pm 4.96,10.86 \pm 3.65$ and $8.85 \pm$ $3.44 \mathrm{ng} / \mathrm{ml}$, respectively, while the production of IL- $1 \beta$ in the group treated with LPS only was $42.39 \pm 5.48 \mathrm{ng} / \mathrm{ml}$, IL-6 productions in LPS-induced RAW 264.7 cells incubated with compound 1 at different concentrations were $25.37 \pm 4.62$, $17.45 \pm 3.67$ and $9.46 \pm 3.34 \mathrm{ng} / \mathrm{ml}$, respectively, IL-6 productions in LPS-induced RAW 264.7 cells incubated with compound 2 at different concentrations were $20.04 \pm 3.20,12.45 \pm 2.84$ and $6.63 \pm 2.37 \mathrm{ng} / \mathrm{ml}$, respectively, and IL-6 productions in LPS-induced RAW 264.7 cells incubated with compound 3 at different concentrations were $17.92 \pm 2.81,10.53 \pm 2.62$ and $5.27 \pm 2.01 \mathrm{ng} / \mathrm{ml}$, respectively, while the production of IL- 6 in the group treated with LPS only was 30.78 $\pm 5.96 \mathrm{ng} / \mathrm{ml}$, IL-10 productions in LPS-induced RAW 264.7 cells incubated with compound 1 at different concentrations were $22.13 \pm 3.64,17.61 \pm 3.56$ and $13.32 \pm 2.34 \mathrm{ng} / \mathrm{ml}$, respectively, IL-10 productions in LPS-induced RAW 264.7 cells incubated with compound 2 at different concentrations were $18.11 \pm 3.07$, $14.06 \pm 2.96$ and $10.72 \pm 2.67 \mathrm{ng} / \mathrm{ml}$, respectively, and IL-10 productions in LPS-induced RAW 264.7 cells incubated with compound 3 at different concentrations were $16.55 \pm 2.22,12.39 \pm 2.07$ and $8.97 \pm 2.05 \mathrm{ng} / \mathrm{ml}$, respectively, while the production of IL-10 in the group treated with LPS only was $28.31 \pm$ $5.69 \mathrm{ng} / \mathrm{ml}$. Therefore, treatment with geldanamycin derivatives $(1,2.5$ and 5 $\mu \mathrm{g} / \mathrm{ml}$ ) remarkably inhibited in a LPS-induced TNF- $\alpha$, IL- $1 \beta$, IL- 6 and IL-10 production in a dose-dependent manner.

\section{Discussion}

LPS was a typical inflammatory stimulus, which could trigger inflammation and activate the cellular signal transduction, and caused the intracelluar cascades [16]. LPS activates macrophages and detects the characteristics of the cells, which is a common means to evaluate the anti-inflammatory activity of many drugs. Therefore, in this study, LPS was utilized to induce macrophage RAW 264.7 cells inflammatory response, and the anti-inflammatory effect of geldanamycin and its derivatives was investigated. The experimental results showed that LPS could activate RAW 264.7 cells effectively, and induced expression of proinflammatory mediators (NO and $\mathrm{PGE}_{2}$ ) and cytokines (TNF- $\alpha$, IL- $1 \beta$, IL-6 and 
IL-10). Furthermore, it also could promote the gene transcription of iNOS, TNF- $\alpha$, IL- $1 \beta$ and IL- 6 mRNA [10]. In addition, the experimental results also showed that the doses of geldanamycin and its derivatives $(1,2.5$ and $5 \mu \mathrm{g} / \mathrm{ml})$ had no effect on the viability of RAW 264.7 cells experimentally. These results further demonstrated the pro-inflammatory effect of LPS on macrophages, and provided a reliable inflammatory model as well as a proper concentration range of geldanamycin and its derivatives for the follow-up experiments.

Inflammatory is a very complex process, including the accumulation of inflammatory cells, proliferation and production of inflammatory mediators and cytokines [17]. Macrophages function by releasing pro-inflammatory mediators and cytokines, such as COX-2, iNOS, MMP-2, MMP-9, NO, PGE 2 , ROS, TNF- $\alpha$, IL-1 $\beta$, IL-6, IL-10 and chemokines (chemokine C-C motif ligand 2; CCL2) [18] [19] [20] [21] [22]. These mediators and cytokines play a principal role in inflammatory diseases and processes [23] [24] [25]. Hence, it is an effective means to prevent the occurrence and development of inflammatory response by blocking the excessive production of these inflammatory mediators and cytokines [26] [27] [28]. TNF- $\alpha$, which can cause pro-inflammatory effects to many types of cells, is produced by macrophages, mononuclear cells and T cells. IL-1 $\beta$, IL-6 and IL-10 are regarded as an endogenous mediator of LPS-induced fever [29] [30]. This study found that, under certain conditions, geldanamycin and its derivatives can significantly reduce the level of these cytokine productions in LPS-induced RAW 264.7 cells. These results suggested that geldanamycin and its derivatives could play an anti-inflammatory role by inhibiting TNF- $\alpha$, IL- $1 \beta$, IL-6 and IL-10 productions. $\mathrm{NO}$ and $\mathrm{PGE}_{2}$ are also produced by inducible nitric oxide synthase (iNOS) and cyclooxygenase (COX-2) respectively [31] [32] [33]. These mediators drive the recruitment and initiation of macrophages and other immune cells to complete a full cycle of inflammation and interfere with metabolic functions [34]. In this study found that LPS can increase the expression of $\mathrm{NO}$ and $\mathrm{PGE}_{2}$ obviously, but if co-incubated with geldanamycin and its derivatives simultaneously, the expression of $\mathrm{NO}$ and $\mathrm{PGE}_{2}$ was significantly decreased and the decrease is dose-dependent. The data demonstrated that geldanamycin and its derivatives can suppress inflammatory response by inhibiting the production of $\mathrm{NO}$ and $\mathrm{PGE}_{2}$ in LPS-stimulated RAW 264.7 cells. In the literatures, geldanamycin has been reported as a potent anti-inflammatory compound that target heat-shock protein 90 and glucose-related protein 96 [35] [36] [37], which act as intracellular chaperones that maintain the structural integrity of cytoplasmic and endoplasmic reticulum-associated proteins, respectively. It binds to, and inactivates the function of, an Hsp90-Hsp70 multichaperone machine [38]. This multisubunit complex maintains the conformation and activity of regulatory kinases (e.g. c-src, cyclin-dependent protein kinase 4 [CDK4], Raf-1, and p38) [39] [40] [41], and nitric oxide synthase (NOS) [42] in eukaryotic cells. Because several Hsp90 substrates promote cellular activation and cell growth by maintanining the structural integrity of kinases such as c-Src, Raf-1, CDK4, extracellular signal-regulated kinase 1, JNK, p38 MAPK, lymphocyte-specific 
protein tyrosine kinase [43], protein kinase $\mathrm{R}$ [44] [45] [46] [47], and transcription factors (e.g. NF-kB) [48] [49], steroid hormone receptors [50] [51] [52], these proteins have potent antiproliferative effects both in vitro and in vivo [53]. Other Hsp90 substrates (e.g. NOS) promote inflammation. Because of this, geldanamycin has potent anti-inflammatory effects [37] [54] by binding to the amino-terminal ATPase domain of Hsp90 and inactivates its function [35] [55]. Inhibition of the function of Hsp90 substrates with the use of geldanamycin has antiproliferative and anti-inflammatory effects [36] [56] [57] [58] [59]. However, geldanamycin was toxic to normal cells, it exhibited hepatotoxicity at its effective concentrations [60], thereby limiting dose regimens should be considered for patient safety with medication administration [61] [62]. As previous studies have verrified that derivatization of geldanamycin by substituting the C17-position of geldanamycin with an amino group has greatly decreased the toxicity while retaining the anti-tumor activity. [63] [64] [65] [66]. According to this effect, numerous geldanamycin derivatives with reduced hepatotoxicity have been designed, and several of them have entered clinical trials to treat patients [67] [68] [69]. In this study, synthetic geldanamycin derivatives devoid of C17 methoxy group by tryptamine and 5'methoxytryptamine substitution could potentially provide new agents with improved toxicity profiles over geldanamycin by increasing the percentage of cell viability with retaining the inhibitory effect of pro-inflammatory cytokines and mediators in LPS-induced RAW 264.7 cells. However, it should be noted that geldanamycin and its derivatives showed to be toxic at the concentration of 10 to $40 \mu \mathrm{g} / \mathrm{ml}$ in LPS-induced RAW 264.7 cells. The reason for this phenomenon is due the benzoquinon moiety which has an affinity for Hsp90 [70].

In this study, the inhibitory effects of geldanamycin derivatives on the productions of proinflammatory cytokines and mediators in LPS-stimulated RAW 264.7 cells were more potent than that of geldanamycin. A literaure review revealed only one study of the anti-inflammotry effects of tryptamine hybrid compounds [71]. The reason for this phenomenon is due to tryptamine group could synergize with geldanamycin in the inhibitory effects on production of inflammatory mediators and proinflammatory cytokines in LPS-stimulated RAW 264.7 cells. In addition, cytotoxic effect of geldanamycin and its derivatives was evaluated in the absence or presence of LPS. When treated alone, these compounds did not affect the cell viability at all concentrations used (1 to 5 $\mu \mathrm{g} / \mathrm{ml}$ ). The potencies of the inhibitory activities of geldanamycin and its derivatives on RAW 264.7 macrophage cells are expected that these compounds would be useful for the treatment of inflammatory diseases that show the increased expression of proinflammatory cytokines and mediators.

The results obtained here demonstrate that the effects of geldanamycin derivatives (17-(tryptamine)-17-demethoxygeldanamycin and (17-(5'-methoxytryptamine)-17-demethoxygeldanamycin) on the productions of proin-flammatory cytokines and mediators in LPS-stimulated RAW 264.7 cells were more potent than that of geldanamycin in a dose-dependant manner with less toxicity. These 
results suggest that tryptamine hybrid geldanamycins can inhibit inflammatory response and may be a potential therapeutic candidate for the treatment of chronic inflammation and autoimmune inflammatory diseases. They could be useful for future drug development.

\section{Acknowledgements}

The authors are grateful to Mr Suttinun Vicharn in the Department of Chemistry, Faculty of Science, Silpakorn University, Thailand, for measuring NMR and MS data, respectively. This work was supported by the Higher Education Research Promotion and National Research University Project of Thailand, Office of the Higher Education Commission, Thailand.

\section{Conflicts of Interest}

The authors declare no conflicts of interest regarding the publication of this paper.

\section{References}

[1] Li, Y.H., Tao, P.Z., Liu, Y.Z. and Jiang, J.D. (2004) Geldanamycin, a Ligand of Heat Shock Protein 90, Inhibits the Replication of Herpes Simplex Virus Type 1 in Vitro. Antimicrobial Agents and Chemotherapy, 48, 867-872. https://doi.org/10.1128/aac.48.3.867-872.2004

[2] Modi, S., Stopeck, A., Linden, H., Solit, D., Chandarlapaty, S., et al. (2011) HSP90 Inhibition Is Effective in Breast Cancer: A Phase II Trial of Tanespimycin (17-AAG) Plus Trastuzumab in Patients with HER2-Positive Metastatic Breast Cancer Progressing on Trastuzumab. Clinical Cancer Research, 17, 5132-5139. https://doi.org/10.1158/1078-0432.ccr-11-0072

[3] Supko, J.G., Hickman, R.L., Grever, M.R. and Malspeis, L. (1995) Preclinical Pharmacologic Evaluation of Geldanamycin as an Antitumor Agent. Cancer Chemotherapy and Pharmacology, 36, 305-315. https://doi.org/10.1007/s002800050328

[4] Kitson, R.R., Chang, C.H., Xiong, R., Williams, H.E., Davis, A.L., et al. (2013) Synthesis of 19-Substituted Geldanamycins with Altered Conformations and Their Binding to Heat Shock Protein Hsp90. Nature Chemistry, 5, 307-314 https://doi.org/10.1038/nchem.1596

[5] Shan, G.Z., Peng, Z.G., Li, Y.H., Li, D., Li, Y.P., et al. (2011) A Novel Class of Geldanamycin Derivatives as HCV Replication Inhibitors Targeting on Hsp90: Synthesis, Structure-Activity Relationships and Anti-HCV Activity in GS4.3 Replicon Cells. Journal of Antibiotics, 64, 177-182.

[6] Li, Y.P., Shan, G.Z., Peng, Z.G., Zhu, J.H., Meng, S., et al. (2010) Synthesis and Biological Evaluation of Heat Shock Protein 90 Inhibitors: Geldanamycin Derivatives with Broad Antiviral Activities. Antiviral Chemistry and Chemotherapy, 20, 259-268. https://doi.org/10.3851/imp1631

[7] Lin, Z., Peng, R., Li, Z., Wang, Y., Lu, C., et al. (2015) 17-ABAG, a Novel Geldanamycin Derivative, Inhibits LNCaP-Cell Proliferation through Heat Shock Protein 90 Inhibition. International Journal of Molecular Medicine, 36, 424-432.

https://doi.org/10.3892/ijmm.2015.2239

[8] Tian, Z.Q., Liu, Y., Zhang, D., Wang, Z., Dong, S.D., et al. (2004) Synthesis and Biological Activities of Novel 17-Aminogeldanamycin Derivatives. Bioorganic and 
Medicinal Chemistry, 12, 5317-5329. https://doi.org/10.1016/j.bmc.2004.07.053

[9] Wrona, I.E., Gozman, A., Taldone, T., Chiosis, G. and Panek, J.S. (2010) Synthesis of Reblastatin, Autolytimycin, and Non-Benzoquinone Analogues: Potent Inhibitors of Heat Shock Protein 90. Journal of Organic Chemistry, 75, 2820-2835. https://doi.org/10.1021/jo1000109

[10] Taechowisan, T., Puckdee, W. and Phutdhawong, W.S. (2019) Streptomyces zerumbet, a Novel Species from Zingiber zerumbet (L.) Smith and Isolation of Its Bioactive Compounds. Advances in Microbiology, 9, 194-219. https://doi.org/10.4236/aim.2019.93015

[11] Kousar, S., Anjuma, S.N., Jaleel, F., Khana, J. and Naseema, S. (2017) Biomedical Significance of Tryptamine: A Review. Journal of Pharmacovigilance, 5, 239. https://doi.org/10.4172/2329-6887.1000239

[12] Pal, C., Bindu, S., Dey, S., Alam, A., Goyal, M., et al. (2012) Tryptamine-Gallic Acid Hybrid Prevents Non-Steroidal Anti-Inflammatory Drug-Induced Gastropathy: Correction of Mitochondrial Dysfunction and Inhibition of Apoptosis in Gastric Mucosal Cells. Journal of Biological Chemistry, 287, 3495-3509. https://doi.org/10.1074/jbc.m111.307199

[13] Green, L.C., Wagner, D.A., Glogowski, J., Skipper, P.L., Wishnok, J.S., et al. (1982) Analysis of Nitrate, Nitrite, and $\left[{ }^{15} \mathrm{~N}\right]$ Nitrate in Biological Fluids. Analytical Biochemistry, 126, 131-138. https://doi.org/10.1016/0003-2697(82)90118-X

[14] Ōmura, S., Nakagawa, A. and Sadakane, N. (1979) Structure of Herbimycin a New Ansamycin Antibiotic. Tetrahedron Letters, 20, 4323-4326. https://doi.org/10.1016/s0040-4039(01)86578-3

[15] Qin, H.L. and Panek, J.S. (2008) Total Synthesis of the Hsp90 Inhibitor Geldanamycin. Organic Letters, 10, 2477-2479. https://doi.org/10.1021/ol800749w

[16] Dunzendorfer, S., Lee, H.K., Soldau, K. and Tobias, P.S. (2004) TLR4 Is the Signaling but Not the Lipopolysaccharide Uptake Receptor. Journal of Immunology, 173, 1166-1170. https://doi.org/10.4049/jimmunol.173.2.1166

[17] Ji, Y. and Qiang, W.G. (2010) Inhibition Effects of Valsartan on Cell Proliferation, Expression Inflammatory Factors and Reactive Oxygen Species Production of $\mathrm{Ma}$ crophages. Journal of Shanghai Jiaotong University (Medical Science), 30, 292-295.

[18] Coussens, L.M. and Werb, Z. (2002) Inflammation and Cancer. Nature, 420, 860-867. https://doi.org/10.1038/nature01322

[19] Babior, B.M. (2000) Phagocytes and Oxidative Stress. American Journal of Medicine, 109, 33-44.

[20] Closa, D. and Folch-Puy, E. (2004) Oxygen Free Radicals and the Systemic Inflammatory Response. International Union of Biochemistry and Molecular Biology Life, 56, 185-191. https://doi.org/10.1080/15216540410001701642

[21] Hussain, S.P., Trivers, G.E., Hofseth, L.J., He, P., Shaikh, I., et al. (2004) Nitric Oxide, a Mediator of Inflammation, Suppresses Tumorigenesis. Cancer Research, 64, 6849-6853. https://doi.org/10.1158/0008-5472.can-04-2201

[22] Hodge, D.R., Hurt, E.M. and Farrar, W.L. (2005) The Role of IL-6 and STAT3 in Inflammation and Cancer. European Journal of Cancer, 41, 2502-2512. https://doi.org/10.1016/j.ejca.2005.08.016

[23] Sarkar, D., Saha, P., Gamre, S., Bhattacharjee, S., Hariharan, C., et al. (2008) Anti-Inflammatory Effect of Allylpyrocatechol in LPS-Induced Macrophages Is Mediated by Suppression of iNOS and COX-2 via the NF- $\mathrm{KB}$ Pathway. International Immunopharmacology, 8, 1264-1271. https://doi.org/10.1016/j.intimp.2008.05.003

[24] Guan, Q. and Zhang, J. (2017) Recent Advances: The Imbalance of Cytokines in the 
Pathogenesis of Inflammatory Bowel Disease. Mediators of Inflammation, 2017, Article ID: 4810258. https://doi.org/10.1155/2017/4810258

[25] Croft, M. and Siegel, R.M. (2017) Beyond TNF: TNF Superfamily Cytokines as Targets for the Treatment of Rheumatic Diseases. Nature Reviews Rheumatology, 13, 217-233. https://doi.org/10.1038/nrrheum.2017.22

[26] Delgado, A.V., Mcmanus, A.T. and Chambers, J.P. (2003) Production of Tumor Necrosis Factor-Alpha, Interleukin 1-Beta, Interleukin 2, and Interleukin 6 by Rat Leukocyte Subpopulations after Exposure to Substance P. Neuropeptides, 37, 355-361. https://doi.org/10.1016/j.npep.2003.09.005

[27] Palomo, J., Dietrich, D., Martin, P., Palmer, G. and Gabay, C. (2015) The Interleukin (IL)-1 Cytokine Family-Balance between Agonists and Antagonists in Inflammatory Diseases. Cytokine, 76, 25-37. https://doi.org/10.1016/j.cyto.2015.06.017

[28] Alunno, A., Carubbi, F., Giacomelli, R. and Gerli, R. (2017) Cytokines in the Pathogenesis of Rheumatoid Arthritis: New Players and Therapeutic Targets. BMC Rheumatology, 1, 3. https://doi.org/10.1186/s41927-017-0001-8

[29] Harden, L.M., Rummel, C., Laburn, H.P., Damm, J., Wiegand, F., et al. (2014) Critical Role for Peripherally-Derived Interleukin-10 in Mediating the Thermoregulatory Manifestations of Fever and Hypothermia in Severe Forms of Lipopolysaccharide-Induced Inflammation. Pflügers Archiv: European Journal of physiology, 466, 1451-1466. https://doi.org/10.1007/s00424-013-1371-4

[30] LeMay, L.G., Vander, A.J. and Kluger, M.J. (1990) Role of Interleukin 6 in Fever in Rats. American Journal of Physiology, 258, 798-803.

https://doi.org/10.1152/ajpregu.1990.258.3.R798

[31] Watkins, L.R., Maier, S.F. and Goehler, L.E. (1995) Immune Activation: The Role of Proinflammatory Cytokines in Inflammation, Illness Responses and Pathological Pain States. Pain, 63, 289-302. https://doi.org/10.1016/0304-3959(95)00186-7

[32] Masferrer, J.L., Zweifel, B.S., Manning, P.T., Hauser, S.D., Leahy, K.M., et al. (1994) Selective Inhibition of Inducible Cyclooxygenase 2 in Vivo Is Anti-Inflammatory and Nonulcerogenic. Proceedings of the National Academy of Sciences of the United States of America, 91, 3228-3232. https://doi.org/10.1073/pnas.91.8.3228

[33] Laveti, D., Kumar, M., Hemalatha, R., Sistla, R., Naidu, V.G. et al. (2013) Anti-inflammatory Treatments for Chronic Diseases: A Review. Inflammation and Allergy Drug Targets, 12, 349-361. https://doi.org/10.2174/18715281113129990053

[34] Monacada, S. and Higgs, A. (1993) The L-Arginine-Nitric Oxide Pathway. The New England Journal of Medicine, 329, 2002-2012. https://doi.org/10.1056/NEJM199312303292706

[35] Roe, S., Prodromou, C., O’Brien, R., Ladbury, J., Piper, P., et al. (1999) Structural Basis for Inhibition of the Hsp90 Molecular Chaperone by the Antitumor Antibiotics Radicicol and Geldanamycin. Journal of Medicinal Chemistry, 42, 260-266. https://doi.org/10.1021/jm980403y

[36] Ochel, H.J., Eichhorn, K. and Gademann, G. (2001) Geldanamycin, the Prototype of a Class of Antitumor Drugs Targeting the Heat Shock Protein 90 Family of Molecular Chaperones. Cell Stress and Chaperones, 6, 105-112.

[37] Bucci, M., Roviezzo, F., Cicala, C., Sessa, W.C. and Cirino, G. (2000) Geldanamycin, an Inhibitor of Heat Shock Protein 90 (Hsp90) Mediated Signal Transduction Has Anti-Inflammatory Effects and Interacts with Glucocorticoid Receptor In Vivo. British Journal of Pharmacology, 131, 13-16. https://doi.org/10.1038/sj.bjp.0703549

[38] Scheufler, C., Brinker, A., Bourenkov, G., Pegoraro, S., Moroder, L., et al. (2000) Structure of TPR Domain-Peptide Complexes, Critical Elements in the Assembly of 
the Hsp70-Hsp90 Multichaperone Machine. Cell, 101, 199-210. https://doi.org/10.1016/S0092-8674(00)80830-2

[39] Davis, M. and Carbott, D. (1999) Herbimycin A and Geldanamycin Inhibit Okadaic Acid-Induced Apoptosis and p38 Activation in NRK-52E Renal Epithelial Cells. Toxicology and Applied Pharmacology, 161, 59-74. https://doi.org/10.1006/taap.1999.8765

[40] Bijlmakers, M.J. and Marsh, M. (2000) Hsp90 Is Essential for the Synthesis and Subsequent Membrane Association, but Not the Maintenance, of the Src-Kinase p56lck. Molecular Biology of the Cell, 11, 1499-1432. https://doi.org/10.1091/mbc.11.5.1585

[41] Richter, K. and Buchner, J. (2001) Hsp90, Chaperoning Signal Transduction. Journal of Cellular Physiology, 188, 281-290. https://doi.org/10.1002/jcp.1131

[42] Pritchard, K.A., Ackerman, A.W., Gross, E.R., Stepp, D.W., Shi, Y., et al. (2001) Heat Shock Protein 90 Mediates the Balance of Nitric Oxide and Superoxide Anion from Endothelial Nitric-Oxide Synthase. Journal of Biological Chemistry, 276, 17621-17624. https://doi.org/10.1074/jbc.C100084200

[43] Marczin, N., Papapetropoulos, A. and Catravas, J.D. (1993) Tyrosine Kinase Inhibitors Suppress Endotoxin- and IL-1 Beta-Induced NO Synthesis in Aortic Smooth Muscle Cells. American Journal of Physiology, 265, 1014-1018. https://doi.org/10.1152/ajpheart.1993.265.3.H1014

[44] Schulte, T.W., An, W.G. and Neckers, L.M. (1997) Geldanamycin-Induced Desta-Bilization of Raf-1 Involves the Proteasome. Biochemical and Biophysical Research Communications, 239, 655-659. https://doi.org/10.1006/bbrc.1997.7527

[45] Pratt, W. (1998) The Hsp90-Based Chaperone System, Involvement in Signal Transduction from a Variety of Hormone and Growth Factor Receptors. Proceedings of the Society for Experimental Biology and Medicine, 217, 420-434. https://doi.org/10.3181/00379727-217-44252

[46] Sakagami, M., Morrison, P. and Welch, W. (1999) Benzoquinoid Ansamycins (Herbimycin A and Geldanamycin) Interfere with the Maturation of Growth Factor Receptor Tyrosine Kinases. Cell Stress and Chaperones, 4, 19-28.

[47] Schnaider, T., Somogyi, J., Csermely, P. and Szamel, M. (2000) The Hsp90-Specific Inhibitor Geldanamycin Selectively Disrupts Kinase-Mediated Signaling Events of T-Lymphocyte Activation. Cell Stress and Chaperones, 5, 52-61.

[48] Malhotra, V., Shanley, T.P., Pittet, J.F., Welch, W.J. and Wong, H.R. (2001) Geldanamycin Inhibits NF- $\kappa$ B Activation and Interleukin-8 Gene Expression in Cultured Human Respiratory Epithelium. American Journal of Respiratory Cell and Molecular biology, 25, 92-97. https://doi.org/10.1165/ajrcmb.25.1.4384

[49] Wong, H.R., Ryan, M. and Wispé, J.R. (1997) Stress Response Decreases NF-kappaB Nuclear Translocation and Increases I-KappaBalpha Expression in A549 Cells. Journal of Clinical Investigation, 99, 2423-2428.

https://doi.org/10.1172/JCI119425

[50] Whitesell, L. and Cook, P. (1996) Stable and Specific Binding of Heat Shock Protein 90 by Geldanamycin Disrupts Glucocorticoid Receptor Function in Intact Cells. Molecular Endocrinology, 10, 705-712. https://doi.org/10.1210/mend.10.6.8776730

[51] Bamberger, C., Wald, M., Bamberger, A. and Schulte, H. (1997) Inhibition of Mineralocorticoid and Glucocorticoid Receptor Function by the Heat Shock Protein 90-Binding Agent Geldanamycin. Molecular and Cellular Endocrinology, 131, 233 240. https://doi.org/10.1016/s0303-7207(97)00115-9

[52] Fliss, A., Benzeno, S., Rao, J. and Caplan, A. (2000) Control of Estrogen Receptor 
Ligand Binding by Hsp90. Journal of Steroid Biochemistry and Molecular Biology, 72, 223-230. https://doi.org/10.1016/s0960-0760(00)00037-6

[53] Neckers, L., Schulte, T. and Mimnaugh, E. (1999) Geldanamycin as a Potential Anti-Cancer Agent, Its Molecular Target and Biochemical Activity. Investigational New Drugs, 17, 361-373. https://doi.org/10.1023/a:1006382320697

[54] Sugita, T., Tanaka, S., Murakami, T., Miyoshi, H. and Ohnuki, T. (2008) Immunosuppressive Effects of the Heat Shock Protein 90-Binding Antibiotic Geldanamycin. Biochemistry and Molecular Biology International, 47, 587-595. https://doi.org/10.1080/15216549900201633

[55] Grenert, J., Sullivan, W., Fadden, P., Haystead, T., Clark, J., et al. (1997) The Amino-Terminal Domain of Heat Shock Protein 90 (Hsp90) That Binds Geldanamycin Is an ATP/ADP Switch Domain That Regulates Hsp90 Conformation. Journal of Biological Chemistry, 272, 23843-23850. https://doi.org/10.1074/jbc.272.38.23843

[56] Mandler, R., Wu, C., Sausville, E., Roettinger, A., Newman, D., et al. (2000) Immunoconjugates of Geldanamycin and Anti-HER2 Monoclonal Antibodies, Antiproliferative Activity on Human Breast Carcinoma Cell Lines. Journal of the National Cancer Institute, 92, 1573-1581. https://doi.org/10.1093/jnci/92.19.1573

[57] Nimmanapalli, R., O’Bryan, E. and Bhalla, K. (2001) Geldanamycin and Its Analogue 17-Allylamino-17-Demethoxygeldanamycin Lowers Bcr-Abl Levels and Induces Apoptosis and Differentiation of Bcr-Abl-Positive Human Leukemic Blasts. Cancer Research, 61, 1799-1804.

[58] Yang, J., Yang, J.M., Iannone, M., Shih, W., Lin Y. and Hait, W. (2001) Disruption of the EF-2 Kinase/Hsp90 Protein Complex: A Possible Mechanism to Inhibit Glioblastoma by Geldanamycin. Cancer Research, 61, 4010-4016.

[59] Murphy, P., Sharp, A., Shin, J., Gavrilyuk, V., Dello, C., et al. (2002) Suppressive Effects of Ansamycins on Inducible Nitric Oxide Synthase Expression and the Development of Experimental Autoimmune Encephalomyelitis. Journal of Neuroscience Research, 67, 461-470. https://doi.org/10.1002/jnr.10139

[60] Fukuyo, Y., Hunt, C.R. and Horikoshi, N. (2010) Geldanamycin and Its Anti-Cancer Activities. Cancer Letters, 290, 24-35. https://doi.org/10.1016/j.canlet.2009.07.010

[61] Dey, A. and Cederbaum, A.I. (2007) Geldanamycin, an Inhibitor of Hsp90 Increases Cytochrome P450 2E1 Mediated Toxicity in HepG2 Cells through Sustained Activation of the p38MAPK Pathway. Archives of Biochemistry and Biophysics, 461, 275-286. https://doi.org/10.1016/j.abb.2007.02.014

[62] Clark, C.B., Rane, M.J., El Mehdi, D., Miller, C.J., Sachleben, L.R., et al. (2009) Role of Oxidative Stress in Geldanamycin-Induced Cytotoxicity and Disruption of Hsp90 Signaling Complex. Free Radical Biology and Medicine, 47, 1440-1449. https://doi.org/10.1016/j.freeradbiomed.2009.08.012

[63] Tian, Z.Q., Liu, Y.Q., Zhang, D., et al. (2004) Synthesis and Biological Activities of Novel 17-Aminogeldanamycin Derivatives. Bioorganic and Medicinal Chemistry, 12, 5317-5329. https://doi.org/10.1016/j.freeradbiomed.2009.08.012

[64] Rastelli, G., Tian, Z.Q., Wang, Z., Myles, D. and Liu, Y. (2005) Structure-Based Design of 7-Carbamate Analogs of Geldanamycin. Bioorganic and Medicinal Chemistry Letters, 15, 5016-5021. https://doi.org/10.1016/j.bmcl.2005.08.013

[65] Banerji, U., Judson, I. and Workman, P. (2003) The Clinical Applications of Heat Shock Protein Inhibitors in Cancer-Present and Future. Current Cancer Drug Targets, 3, 385-390. https://doi.org/10.2174/1568009033481813

[66] Li, Z., Jia, L., Wang, J., Wu, X., Hao, H., et al. (2014) Design, Synthesis and Biologi- 
cal Evaluation of 17-Arylmethylamine-17-Demethoxygeldanamycin Derivatives as Potent Hsp90 Inhibitors. European Journal of Medicinal Chemistry, 85, 359-370. https://doi.org/10.1016/j.ejmech.2014.07.101

[67] Heath, E.I., Hillman, D.W., Vaishampayan, U., Sheng, S., Sarkar, F., et al. (2008) A Phase II Trial of 17-Allylamino-17-Demethoxygeldanamycin in Patients with Hormone-Refractory Metastatic Prostate Cancer. Clinical Cancer Research, 14, 79407946. https://doi.org/10.1158/1078-0432.ccr-08-0221

[68] Pacey, S., Wilson, R.H., Walton, M., Eatock, M.M., Hardcastle, A., et al. (2011) A Phase I Study of The Heat Shock Protein 90 Inhibitor Alvespimycin (17-DMAG) Given Intravenously to Patients with Advanced Solid Tumors. Clinical Cancer Research, 17, 1561-1570. https://doi.org/10.1158/1078-0432.ccr-10-1927

[69] Oh, W.K., Galsky, M.D., Stadler, W.M., Srinivas, S., Chu, F., et al. (2011) Multicenter Phase II Trial of The Heat Shock Protein 90 Inhibitor, Retaspimycin Hydrochloride (IPI-504), in Patients with Castration-Resistant Prostate Cancer. Urology, 78, 626-630. https://doi.org/10.1016/j.urology.2011.04.041

[70] Neckers, L. (2002) Hsp90 Inhibitors as Novel Cancer Chemotherapeutic Agents. Trends in Molecular Medicine, 8, S55-S61. https://doi.org/10.1016/s1471-4914(02)02316-x

[71] Jung, E.H., Hwang, J.S., Kwon, M.Y., Kim, K.H., Cho, H., et al. (2016) A Tryptamine-Paeonol Hybridization Compound Inhibits LPS-Mediated Inflammation in BV2 Cells. Neurochemistry International, 100, 35-43.

https://doi.org/10.1016/j.neuint.2016.08.010 